\title{
Clinical Studies with Traditional Chinese Medicine in the Past Decade and Future Research and Development
}

Authors

Affiliations
Miao Jiang ${ }^{1}$, Jing Yang ${ }^{1}$, Chi Zhang ${ }^{1}$, Baoyan Liu ${ }^{1}$, Kelvin Chan ${ }^{2}$, Hongxin Cao ${ }^{1}$, Aiping Lu ${ }^{1}$

${ }^{1}$ Disease and TCM Pattern Correlation Research Department, China Academy of Chinese Medical Sciences, Beijing, People's Republic of China

${ }^{2}$ Herbal Medicine Research and Education Center, The University of Sydney, and CompleMED University of Western Sydney, Sydney, NSW, Australia
Key words

- traditional Chinese medicine

- clinical trials

- systematic review

received February 19, 2010

revised Sept. 18, 2010

accepted Sept. 21, 2010

\section{Bibliography}

DOI http://dx.doi.org/

10.1055/s-0030-1250456

Published online October 26, 2010

Planta Med 2010; 76:

2048-2064 ๑ Georg Thieme

Verlag KG Stuttgart · New York . ISSN 0032-0943

\section{Correspondence}

\section{Prof. Hongxin Cao, MD}

TCM Clinical Research

Department

China Academy

of Chinese Medical Sciences Beijing 100700

People's Republic of China

Phone: + 861064014411-2205

Fax: +861064032659

caohongxin898@hotmail.com

\section{Correspondence}

Prof. Aiping Lu, MD

Disease and TCM Pattern Correlation Research Department China Academy

of Chinese Medical Sciences

Beijing 100700

People's Republic of China

Phone: + 861064067611

Fax: +861084032881

lap64067611@126.com

\section{Abstract}

$\nabla$

Traditional Chinese medicine (TCM) is currently considered a complementary or alternative medical system in most Western countries and has been increasingly accepted worldwide. More and more clinical trials on TCM have been conducted internationally, and scientists worldwide are becoming increasingly interested in the evaluation of clinical efficacy of TCM based on clinical trials. This paper reviews the situation of clinical trials on TCM in the past decade, including systematic reviews about clinical trials either focusing on the treatment of disease with TCM approaches or focusing on one herbal product, conduction of clinical trials on TCM either with randomization and controlled methods or general observation. Some general issues on the conduct of clinical trials on TCM, such as randomization, control, quality of life (QOL), patient reported outcomes (PROs) and biomarkers, quality control, safety evaluation and case studies, are discussed, and accordingly some suggestions are proposed.

\section{Abbreviations \\ $\nabla$}

ADRs: adverse drug reactions

BCS: best case series

CAM: complementary and alternative medicine

CHICTR: Chinese clinical trial registry

CHM: $\quad$ Chinese herbal medicine

ChQOL: Chinese medicine-based QOL

\section{Introduction}

$\nabla$

Traditional Chinese medicine (TCM) is an essential part of the health care system in several Asian countries, and is considered a complementary or alternative medical system in most Western
CMM: Chinese materia medica

DCQD: Da Cheng Qi decoction

DCT: $\quad$ Ding Chuan Tang

DJW: Duhuo Jisheng Wan

EBM: evidence-based medicine

FDA: $\quad$ US Food and Drug Administration

GI: gastrointestinal

HCMV: human cytomegalovirus

HET: Hochu-ekki-to

HJT: $\quad$ He Jie Tang

HRQOL: health-related QOL

JQH: Jianpi Qingre Huayu recipe

JYBDG: Jinye Baidu granule

LCQ: Leicester cough questionnaire

NCI: $\quad$ National Cancer Institute

OCCAM: Office of Cancer Complementary

and Alternative Medicine

PMS: premenstrual syndrome

PROs: patient reported outcomes

PTSD: $\quad$ post-traumatic stress disorder

QOL: $\quad$ quailty of life

RCTs: randomized controlled trials

SAP: $\quad$ severe acute pancreatitis

SOP: $\quad$ standardized operating procedures

SRs: $\quad$ systematic reviews

SWT: $\quad$ Si Wu Tang

SXL: $\quad$ Shengxueling

TBIL: total bilirubin

TCM: traditional Chinese medicine

TDT: $\quad$ trilogy detoxicating therapy

TwHF: $\quad$ Tripterygium wilfordii Hook F

TZYGD: Tiaozhi Yanggan decoction

YSC: Yishen capsule countries. It is a holistic approach to health that attempts to bring the body, mind, and spirit into harmony.

Currently, TCM has been increasingly accepted worldwide. A widespread use of TCM in the treatment of multiple diseases as well as in exploring 
the mechanism of Chinese herbal medicines and acupuncture treatment has produced a massive literature in both clinical and experimental fields.

In the past decade, since the first systematic review of TCM clinical research was published in 2002 [1], more clinical trials have also been published internationally, and this has consequently increased the number of systematic reviews (SRs) and metaanalyses of TCM clinical trials.

- Fig. 1 shows the number of citations searched from PubMed on TCM clinical trials from 1999 to 2009. The figure reached its peak in 2004, but has declined gradually since 2005 probably due to tightened and more stringent requirements for clinical trials. This, however, appears to increase both the level and the quality of papers published.

Following the principle of evidence-based medicine, concrete evidence is needed to evaluate the efficacy of TCM [2]. Randomized controlled trials (RCTs) are regarded as a golden clinical trial design. Since 2002, more and well-designed RCTs have been conducted worldwide to evaluate the efficacy of TCM.

- Fig. 2 shows that the number of papers on the use of RCT on TCM in PubMed has been increasing since 2002. These clinical trials have provided numerous and relatively higher quality data for the evaluation of TCM efficacy. At present, scientists worldwide are becoming increasingly interested in the use of RCTs for TCM, with more projects being initiated to obtain further evidence on the efficacy and safety of TCM.

In China, with the strong support for and strict regulation of TCM clinical trials from governmental authorities, the researchers have paid more attention to the quality. It has been estimated that there are more than 50 TCM clinical trials ongoing that are sponsored by the National Key Technology R \& D Program in China [http://www.most.gov.cn/eng/programmes1/200610/t20061009 _36224.htm].

This paper is intended to review the clinical trials of TCM in the past decade and to provide references to TCM clinical trials and efficacy evaluation.

\section{Systematic Reviews of TCM Clinical Trials \\ $\nabla$}

It was common for journals to publish literature reviews in which experts summarized topical information for the readers. Today, systematic reviews (SRs) tend to replace traditional narrative reviews and expert commentaries, as a more reliable and valid way of summarizing research evidence [3]. SRs may or may not include a statistical synthesis called meta-analysis, depending on whether the studies are similar enough so that combining their results is meaningful [4]. With the development of evidencebased medicine, the Cochrane Collaboration was founded in 1993, and has become one of the best-known organizations that provides an international infrastructure for conducting, maintaining, and updating SRs to evaluate the effectiveness of health care interventions. However, because the SRs overseen by the Cochrane Collaboration are not comprehensive, many journals also publish SRs on relevant topics besides narrative literature reviews.

In the era of evidence-based medicine, Chinese scholars began to advocate developing SRs of TCM [5]. Since 1999, there has been an increasing number of SRs/meta-analyses of TCM. And there is an upward trend in reviews produced by Chinese reviewers. The themes of these SRs are often around medicinal products (single
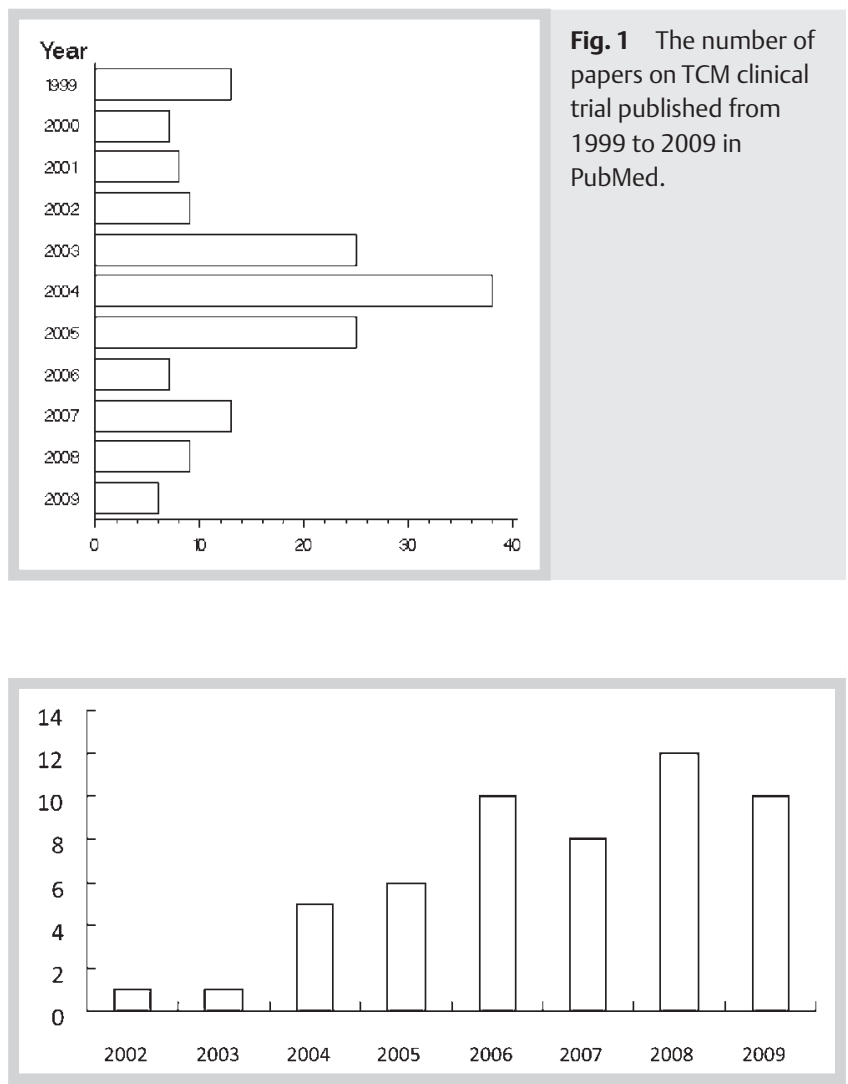

Fig. 2 The numbers of RCT papers on TCM published from 2002 to 2009 in PubMed.

herbal medicines or Chinese proprietary medicines) and diseases.

With the increase in the number of SRs, some Western scholars are now concerned about the quality of TCM reviews and trials [6] as not all published SRs were produced with meticulous care; therefore, their conclusions may sometimes be misleading, and interrogating published reports by asking a series of questions can uncover deficiencies [3]. In this review, we are concerned about the object identity, those relating to the disease, the type and number of included trials, the number of patients, methodology of SRs and meta-analyses.

\section{Systematic reviews focused on diseases}

Many SRs on diseases have been conducted to evaluate the effectiveness of TCM. We applied a rigorous and systematic methodology to evaluate the validity of these SRs, which would, not only reveal problems in applying such methodology to TCM efficacy evaluation, but also serve as an impetus for quality improvement in TCM clinical trials.

Methods and results: We searched PubMed and the Cochrane Library to retrieve all SRs of TCM published in Chinese or English from 1999 to 2009.

According to the results of the abstracts, we chose MEDLINE to get the full text because it is the National Library of Medicine's premier bibliographic database. Most of the high quality studies in TCM from many countries are indexed in Medline.

The search strategy for the Pubmed was an "OR" combination of the terms "traditional Chinese medicine", "Chinese herbal medicine ", and "Chinese medicine". All the search results were then 
Table 1 Systematic reviews on diseases treated with TCM in the past 10 years in PubMed.

\begin{tabular}{|c|c|c|c|c|c|}
\hline Diseases & $\begin{array}{l}\text { Published year } \\
\text { (year limited } \\
\text { of literatures) }\end{array}$ & $\begin{array}{l}\text { Study no. } \\
\text { included }\end{array}$ & Intervention & Main conclusion & Insufficiency \\
\hline $\begin{array}{l}\text { Acute upper respiratory } \\
\text { tract infection [7] }\end{array}$ & 2009 & 13 & $\begin{array}{l}\text { TCM treatment group vs. } \\
\text { control group }\end{array}$ & $\begin{array}{l}\text { Effective without } \\
\text { adverse reactions }\end{array}$ & $\begin{array}{l}\text { Lack of placebo-controlled } \\
\text { and blank-controlled } \\
\text { studies }\end{array}$ \\
\hline Influenza [21] & 2006 & 8 & $\begin{array}{l}\text { TCM treatment vs. antiviral or } \\
\text { antipyretic-analgesic drugs or } \\
\text { the combination of them }\end{array}$ & $\begin{array}{l}\text { No summary meta- } \\
\text { analysis and no } \\
\text { conclusion }\end{array}$ & Low quality \\
\hline \multirow[t]{2}{*}{$\begin{array}{l}\text { Severe acute respiratory } \\
\text { syndrome }[8,22]\end{array}$} & 2005 & 8 & $\begin{array}{l}\text { Integrative traditional Chinese } \\
\text { and Western medicine vs. } \\
\text { Western medicine }\end{array}$ & $\begin{array}{l}\text { No affirmative } \\
\text { conclusion }\end{array}$ & Low quality \\
\hline & 2004 & 6 & $\begin{array}{l}\text { Integrated traditional Chinese } \\
\text { and Western medicine }\end{array}$ & Effective & $\begin{array}{l}\text { Limited available } \\
\text { randomized control trials }\end{array}$ \\
\hline Type 2 diabetes mellitus [23] & $\begin{array}{l}2004 \\
(-2004.4)\end{array}$ & 66 & $\begin{array}{l}\text { Chinese herbal medicines vs. } \\
\text { placebo, pharmacological or } \\
\text { non-pharmacological } \\
\text { interventions }\end{array}$ & $\begin{array}{l}\text { Some herbals have } \\
\text { hypoglycemic ef- } \\
\text { fects }\end{array}$ & $\begin{array}{l}\text { Low methodological quality, } \\
\text { small sample size, and limited } \\
\text { number of trials }\end{array}$ \\
\hline Rheumatoid arthritis [35] & $\begin{array}{l}2009(2000- \\
2007.6)\end{array}$ & 20 & $\begin{array}{l}\text { Herbal medicinal products vs. } \\
\text { inert (placebo) or active controls } \\
\text { treatments }\end{array}$ & $\begin{array}{l}\text { Neither recommend } \\
\text { nor discourage } \\
\text { herbal use }\end{array}$ & $\begin{array}{l}\text { Lack of evidence } \\
\text { of effectiveness }\end{array}$ \\
\hline Ischemic stroke [24] & 2007 & 191 & $\begin{array}{l}\text { Chinese patent medicine vs. } \\
\text { control medicine }\end{array}$ & $\begin{array}{l}\text { No affirmative } \\
\text { conclusion }\end{array}$ & $\begin{array}{l}\text { Poor methodology } \\
\text { quality }\end{array}$ \\
\hline Acute pancreatitis [25] & $\begin{array}{l}2005 \\
(2002.9- \\
2003.10)\end{array}$ & 11 & $\begin{array}{l}\text { Chinese medicinal herbs or Chi- } \\
\text { nese medicinal herbs plus con- } \\
\text { ventional treatment vs. conven- } \\
\text { tional treatment }\end{array}$ & $\begin{array}{l}\text { Cannot recommend } \\
\text { any single herb }\end{array}$ & $\begin{array}{l}\text { Low quality, large } \\
\text { heterogeneity }\end{array}$ \\
\hline Chronic prostatitis [26] & $\begin{array}{l}2006 \\
(1994.1- \\
2003.12)\end{array}$ & 19 & $\begin{array}{l}\text { Chinese herbs orally treated, } \\
\text { Chinese herbs externally treated, } \\
\text { Chinese herbs orally and externally } \\
\text { treated, and integrated Western } \\
\text { with Chinese herbs treated vs. } \\
\text { Western medicine }\end{array}$ & $\begin{array}{l}\text { Failed to prove the } \\
\text { effectiveness of TCM }\end{array}$ & $\begin{array}{l}\text { Low quality, positive } \\
\text { publication bias }\end{array}$ \\
\hline $\begin{array}{l}\text { Dysfunctional uterine } \\
\text { bleeding [9] }\end{array}$ & 2009 & 4 & $\begin{array}{l}\text { CHM vs. no treatment, placebo, } \\
\text { conventional Western medicine, } \\
\text { or general nonspecific surgical } \\
\text { treatment }\end{array}$ & $\begin{array}{l}\text { Comparative } \\
\text { effectiveness with } \\
\text { CWM }\end{array}$ & Low quality, few RCTs \\
\hline Primary dysmenorrhea [10] & $\begin{array}{l}2008 \\
(1950-2007)\end{array}$ & 39 & $\begin{array}{l}\text { CHM vs. placebo, no treatment, } \\
\text { and other treatment }\end{array}$ & Effective & $\begin{array}{l}\text { Low methodological quality, } \\
\text { small sample size }\end{array}$ \\
\hline Schizophrenia [11] & $2005(-2004)$ & 7 & $\begin{array}{l}\text { CHM used alone or combined with } \\
\text { antipsychotic drugs vs. placebo/no } \\
\text { treatment or antipsychotic drugs }\end{array}$ & $\begin{array}{l}\text { Effectiveness } \\
\text { combined with } \\
\text { antipsychotics }\end{array}$ & Few RCTs, need further study \\
\hline Dementia [12] & $\begin{array}{l}2009 \\
(-2007.2)\end{array}$ & 13 & $\begin{array}{l}\text { Herbal medicine with placebo, } \\
\text { no intervention or other therapy }\end{array}$ & Effective and safe & \\
\hline Alzheimer disease [27] & $\begin{array}{l}2007 \\
(1994-2004)\end{array}$ & 40 & TCM vs. Western medicine & $\begin{array}{l}\text { The external validity } \\
\text { would be compro- } \\
\text { mised }\end{array}$ & Low quality, heterogeneity \\
\hline Mild Cognitive Impairment [13] & 2008 & 10 & $\begin{array}{l}\text { Orally administered CHM vs. } \\
\text { placebo, no intervention or } \\
\text { other therapy }\end{array}$ & $\begin{array}{l}\text { Effective without no } \\
\text { severe adverse event }\end{array}$ & $\begin{array}{l}\text { Methodological and data } \\
\text { reporting issues }\end{array}$ \\
\hline Parkinson's disease [28] & $\begin{array}{l}2005 \\
(1979-2000)\end{array}$ & 15 & & $\begin{array}{l}\text { Methodological de- } \\
\text { sign should be } \\
\text { strengthened }\end{array}$ & $\begin{array}{l}\text { Some problems of key links } \\
\text { concerning samples' homo- } \\
\text { geneity, outcome indexes } \\
\text { selection, conclusion } \\
\text { deduction }\end{array}$ \\
\hline Epilepsy [36] & $\begin{array}{l}2009 \\
(1950-2007)\end{array}$ & 5 & $\begin{array}{l}\text { TCM vs. no intervention, place- } \\
\text { bo or single Western medicine } \\
\text { (monotherapy) }\end{array}$ & $\begin{array}{l}\text { Failure in proving the } \\
\text { effectiveness of TCM }\end{array}$ & $\begin{array}{l}\text { Poor methodological quality } \\
\text { and a high probability of } \\
\text { selection, detection and } \\
\text { performance bias, few RCT }\end{array}$ \\
\hline $\begin{array}{l}\text { Attention deficit } \\
\text { hyperactivity disorders [14] }\end{array}$ & 2009 & 34 & TCM vs. methylphenidate & Effectiveness & $\begin{array}{l}\text { Lack of high-quality } \\
\text { clinical trials }\end{array}$ \\
\hline Vitiligo [29] & $\begin{array}{l}2008 \\
(-2007.8)\end{array}$ & 3 & $\begin{array}{l}\text { TCM vs. conventional biomedi- } \\
\text { cal treatment }\end{array}$ & $\begin{array}{l}\text { No meta-analysis } \\
\text { summary and no } \\
\text { conclusion }\end{array}$ & $\begin{array}{l}\text { Varying and poorly described } \\
\text { treatments, small treatment } \\
\text { group size, and inconsistent } \\
\text { outcome measures }\end{array}$ \\
\hline
\end{tabular}


Table 1 Systematic reviews on diseases treated with TCM in the past 10 years in PubMed. (continued)

\begin{tabular}{|c|c|c|c|c|c|}
\hline Diseases & $\begin{array}{l}\text { Published year } \\
\text { (year limited } \\
\text { of literatures) }\end{array}$ & $\begin{array}{l}\text { Study no. } \\
\text { included }\end{array}$ & Intervention & Main conclusion & Insufficiency \\
\hline Premenstrual syndrome [30] & $\begin{array}{l}2009(1950.1- \\
2007.12)\end{array}$ & 2 & TCM vs. control treatment & No final conclusion & $\begin{array}{l}\text { Lack of more and well- } \\
\text { controlled, large trials }\end{array}$ \\
\hline Endometriosis [15] & $\begin{array}{l}2009 \\
(-2009.4)\end{array}$ & 2 & $\begin{array}{l}\text { CHM versus placebo, biomedical } \\
\text { treatment, another } \mathrm{CHM} \text { inter- } \\
\text { vention, or } \mathrm{CHM} \text { plus biomedical } \\
\text { treatment versus biomedical } \\
\text { treatment }\end{array}$ & $\begin{array}{l}\text { Effective with fewer } \\
\text { side effects }\end{array}$ & More rigorous research \\
\hline Ectopic pregnancy [31] & $\begin{array}{l}2007 \\
(-2006.3)\end{array}$ & 2 & $\begin{array}{l}\text { CHM combined with western } \\
\text { medicine vs. CHM or WM }\end{array}$ & $\begin{array}{l}\text { No affirmative } \\
\text { conclusion }\end{array}$ & $\begin{array}{l}\text { Poor methodological quality } \\
\text { with a high risk of conflicted } \\
\text { interest and potential for bias }\end{array}$ \\
\hline Hyperthyroidism [32] & 2007 & 13 & $\begin{array}{l}\text { Chinese herbal medicines alone } \\
\text { vs. Chinese herbal medicines } \\
\text { combined with antithyroid } \\
\text { drugs, radioiodine or both }\end{array}$ & $\begin{array}{l}\text { Have therapeutic } \\
\text { potential but no } \\
\text { affirmative con- } \\
\text { clusion }\end{array}$ & Low methodological quality \\
\hline $\begin{array}{l}\text { Poststroke motor } \\
\text { dysfunction }[37,24]\end{array}$ & $\begin{array}{l}2009 \\
(-2007.12)\end{array}$ & 34 & $\begin{array}{l}\text { Complex Traditional Chinese } \\
\text { Medicine included at least acu- } \\
\text { puncture and Chinese herbal } \\
\text { medicine }\end{array}$ & $\begin{array}{l}\text { No meta-analysis } \\
\text { summary and } \\
\text { no final conclusion }\end{array}$ & $\begin{array}{l}\text { Strong publication bias, } \\
\text { clinical and methodological } \\
\text { heterogeneity, inadequately } \\
\text { designed trials }\end{array}$ \\
\hline $\begin{array}{l}\text { Nasopharyngeal } \\
\text { carcinoma [16] }\end{array}$ & $\begin{array}{l}2007(1966- \\
2007.11)\end{array}$ & 18 & $\begin{array}{l}\text { TCM combined with conventional } \\
\text { cancer therapy vs. conventional } \\
\text { cancer therapy alone }\end{array}$ & $\begin{array}{l}\text { Effective as a } \\
\text { concomitant } \\
\text { therapy }\end{array}$ & $\begin{array}{l}\text { Lack of more rigorously } \\
\text { controlled trials }\end{array}$ \\
\hline Esophageal cancer [33] & $\begin{array}{l}2007 \\
(-2004.6)\end{array}$ & 2 & $\begin{array}{l}\text { CHM plus radiotherapy or } \\
\text { chemotherapy vs. radiotherapy } \\
\text { or chemotherapy }\end{array}$ & $\begin{array}{l}\text { No final conclusion and } \\
\text { more high-quality trials } \\
\text { are needed }\end{array}$ & Low quality \\
\hline $\begin{array}{l}\text { Unresectable } \\
\text { hepatocellular } \\
\text { carcinoma [17] }\end{array}$ & 2007 & 37 & $\begin{array}{l}\text { TCM plus transcatheter arterial } \\
\text { chemoembolization (TACE) vs. } \\
\text { TACE alone }\end{array}$ & Effective & $\begin{array}{l}\text { Methodological quality, } \\
\text { lack of large-scale trial }\end{array}$ \\
\hline Cancer pain [18] & $\begin{array}{l}2007 \\
(1986-2006)\end{array}$ & 41 & $\begin{array}{l}\text { CHM vs. conventional analgesics } \\
\text { and the others using placebo } \\
\text { controls }\end{array}$ & Effective & $\begin{array}{l}\text { Low quality, lack of more } \\
\text { research using rigorously } \\
\text { controlled clinical trial design }\end{array}$ \\
\hline \multirow[t]{2}{*}{ Chronic hepatitis B $[19,20]$} & 2008 & 7 & $\begin{array}{l}\text { Lamivudine combined with TCM } \\
\text { vs. lamivudine }\end{array}$ & $\begin{array}{l}\text { Effective for increasing } \\
\text { the } \mathrm{HBeAg} \text { conversion } \\
\text { rate }\end{array}$ & $\begin{array}{l}\text { Lack of being more specific } \\
\text { to the types of trials }\end{array}$ \\
\hline & 2002 & 27 & $\begin{array}{l}\text { TCM or TCM combined with inter- } \\
\text { feron alfa vs. interferon alfa }\end{array}$ & $\begin{array}{l}\text { Effective for increasing } \\
\text { seroreversion of HBsAg, } \\
\text { HBeAg, and HBV DNA }\end{array}$ & Low quality \\
\hline $\begin{array}{l}\text { Helicobacter pylori } \\
\text { infection [34] }\end{array}$ & 2009 & 6 & $\begin{array}{l}\text { TCM with proton pump inhibitor } \\
\text { or colloidal bismuth subcitrate- } \\
\text { based triple therapy }\end{array}$ & $\begin{array}{l}\text { No meta-analysis } \\
\text { summary; did not } \\
\text { show effectiveness } \\
\text { in H. pylori treat- } \\
\text { ment }\end{array}$ & $\begin{array}{l}\text { Low quality, clinical } \\
\text { heterogeneity and } \\
\text { substantial statistical } \\
\text { heterogeneity }\end{array}$ \\
\hline
\end{tabular}

limited to the reports of "review" and "meta-analysis" published between 1999 and Sept. 2009.

We also searched The Cochrane Library for SRs of TCM clinical trials, and then hand searched the above combined search results. After training in the use of Cochrane analysis, two authors (Jing Yang and Miao Jiang) collected information of these SRs separately. Discrepancies were settled by a third party, one of the principal investigators (Aiping Lu). The information included the general characteristics of SRs, treated clinical problem, their results and their author' conclusions, pattern classification, efficacy of treatment and safety assessment. The basic information of SRs is as follows ( $\odot$ Table 1 ).

The first TCM SRs were published in early 2002. The number of SRs has increased over the past 10 years. We compared the time trend of reviews labeled as "systematic" in the PubMed database (papers in PubMed are considered to be relatively high-quality papers) and Cochrane SR ( Fig. 3), which shows the leap of SRs published. Data on characteristics of SRs was extracted from 31 articles. We identified these reports on the effectiveness and safety assessment.

In total, 29 common diseases were studied in 31 SRs of TCM. All trials in SRs were controlled. The interventions used in the treatment and control groups varied drastically. Altogether, 703 randomized controlled trials were included. Ten SRs were Cochrane reviews. But 16 did not assess the quality of included randomized trials and a further 22 performed only simple and non-standard quality assessments of the included trials. In most of the SRs, the disease was defined and diagnosed according to conventional medicine, and therapeutic outcomes were assessed with quantitative or qualitative (or both) methods of conventional medicine, often combined with traditional Chinese methods. 


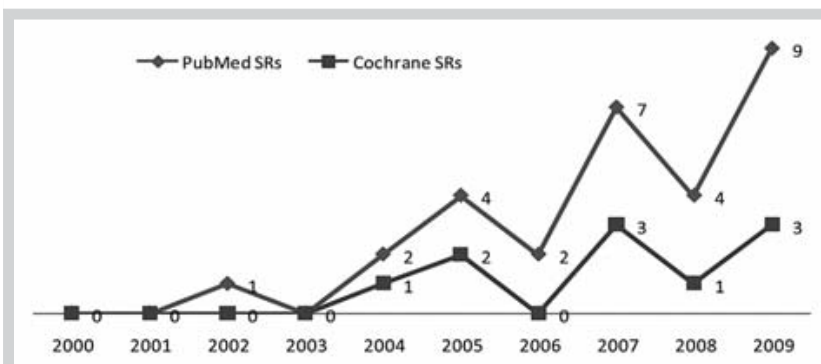

Fig. 3 The time trends of reviews labeled as "systematic" in the PubMed database and Cochrane SR. in past 10 years.

The following 12 diseases were concluded to be supportive of TCM efficacy in the reviews: acute upper respiratory tract infection [7], severe acute respiratory syndrome [8], dysfunctional uterine bleeding [9], primary dysmenorrhea [10], schizophrenia [11], dementia [12], mild cognitive impairment [13], attention deficit hyperactivity disorders [14], endometriosis [15], nasopharyngeal carcinoma [16], unresectable hepatocellular carcinoma [17], cancer pain [18] and chronic hepatitis B $[19,20]$. The interventions in these trials mostly integrated traditional Chinese and Western medicine.

Furthermore, some SRs could not give a final conclusion, such as on influenza [21], severe acute respiratory syndrome [8,22], type 2 diabetes mellitus [23], ischemic stroke [24], acute pancreatitis [25], chronic prostatitis [26], Alzheimer's disease [27], Parkinson's disease [28], vitiligo [29], premenstrual syndrome [30], ectopic pregnancy [31], hyperthyroidism [32], esophageal cancer [33], and Helicobacter pylori infection [34]. And for rheumatoid arthritis, neither recommendation nor discouragement is offered for herbal application [35]. In fact, these results are closely related to the quality of research.

Although the methodological quality of TCM trials has been much improved over the years, there are still many problems. For example, the method of randomization was often inappropriately described; only a few studies had sample sizes over 200; or effectiveness was rarely quantitatively expressed and reported. Over half did not report data on baseline characteristics or on side effects. Most SRs claimed that they could not give strong supporting conclusions, indicating that publication bias may be common. Funnel plots of the 31 SRs in the treatment of diseases confirmed the selective publication of positive trials, suggesting that TCM may not be more effective than the control treatments. Comments: The quality of TCM clinical trials must be improved urgently. Large and well-designed, randomized, controlled trials on long-term major outcomes should be funded. Because of the characteristics of TCM, SRs of TCM should focus on a specific topic, avoid the selection of too many herbal preparations, and pay more attention to interventional evaluation.

SRs of TCM with high-quality data are needed and the SRs will only be produced through the concerted efforts of clinicians, practitioners, and methodologists. Subsequently, such studies may serve as models for future trials in the area. TCM treatments to be tested should be selected carefully, and the potentially important treatments are priority treatments for efficacy evaluation. And the best evidence should be systematically reviewed, summarized, and disseminated, and it may be a good evidencebased approach in TCM.
Systematic reviews focused on herbal preparations

Because of the large number of Chinese herbs used and the varied usage recommended by practitioners, it is difficult to comment on Chinese herbal medicine as a whole. There may be some individual herbs or extracts that play their roles in the treatment and prevention of diseases when combined with conventional treatment. However, more research is needed to determine the effectiveness of these Chinese herbs.

Methods and results: Full details of all methods used and the predefined inclusion criteria are given above in the section "Systematic reviews on diseases". The basic information of SRs is shown in Table 2. Data on characteristics of SRs were extracted from 11 articles. We identified these reports on effectiveness and safety assessment of herbal preparations.

In total, 10 types of Chinese herbs and 313 studies were included. In these SRs, the 6 Chinese herbal products were given positive findings. They were puerarin injection [38], compound salvia pellet [39], Danqi Piantang Jiaonang [40], Maxing Shigan Decoction [41], Aidi injection [42], and Modified Xiaoyao San [43]. Most of these trials combined with other interventions. At the same time, some SRs were not able to give a final conclusion, such as DanShen [44], Tong Xin Luo [45], Shengmai [46], kidney-tonifying and blood-activating prescription [47].

Comments: The amount of literature on systematic evaluation and meta-analyses of Chinese herbs has gradually increased since 2005. But the quality of meta-analyses is still nowhere close to being high or excellent. Many problems remain in these SRs. Only a few studies had sample sizes of 100 subjects or more. Few reports on the adverse reactions were noted in the SRs. Some herbs and herbal formulations have been evaluated in human studies in both the East and the West with wide-ranging results. Research results vary widely depending on the specific herb.

There is some evidence from the SRs that some Chinese herbs may contribute to effectiveness especially when combined with conventional treatment. Many of these clinical trials, however, are published in Chinese, and some of them do not list the ingredients that were evaluated. Some of these papers fail to describe how the studies were conducted in sufficient details to determine comparability with other similar studies. More controlled clinical research is needed to determine the role of Chinese herbal medicine in the treatment and prevention of diseases.

\section{Summary}

In this part, we reviewed the SRs/meta-analyses published in the past 10 years on the development of TCM studies, with focus on those relating to the disease, the type and number of included trials, the number of patients and so forth, but not too much emphasis put on report quality according to tools such as Sack's Quality Assessment Checklist.

Our aim is to review TCM clinical studies in the past 10 years and provide references for further clinical studies. SRs can provide certain information and it is not until very recently that SRs and meta-analyses of TCM were initiated by a few researchers and participants to join in the project at the beginning, and the financial support was insufficient at that time. In the past decade, especially in the last 7 years, where more funding has been secured for scientists to carry out SRs for the evaluation of the efficacy of TCM in the treatment and prevention of diseases. The quality of reporting SR/meta-analyses has also improved in recent papers. The reporting of Cochrane reviews is peer-reviewed and more recognized in comparison with the paper-based articles. However, there is still room for improvement for the quality of reporting 
Table 2 Meta analysis of Chinese herbal medicines treating related diseases over 10 years in PubMed.

\begin{tabular}{|c|c|c|c|c|c|c|}
\hline Herbal medicine & $\begin{array}{l}\text { Year limited } \\
\text { of literatures }\end{array}$ & $\begin{array}{l}\text { Studies No. } \\
\text { included }\end{array}$ & Study drugs & Indication & Main conclusion & Insufficiency \\
\hline \multirow[t]{2}{*}{ Dan Shen $[48,44]$} & 1998-2007 & 150 & DanShen vs. other therapy & $\begin{array}{l}\text { Ischemic vascular } \\
\text { disease }\end{array}$ & $\begin{array}{l}\text { Only } 10 \text { RCTs were iden- } \\
\text { tified with high quality. } \\
\text { The quality of DanShen RCT } \\
\text { in main China has not been } \\
\text { improved significantly over } \\
\text { recent years }\end{array}$ & Low quality \\
\hline & 1979-2006 & 6 & $\begin{array}{l}\text { Dan Shen agents vs. placebo } \\
\text { or open control }\end{array}$ & $\begin{array}{l}\text { Acute ischemic } \\
\text { stroke }\end{array}$ & $\begin{array}{l}\text { No affirmative } \\
\text { conclusion }\end{array}$ & $\begin{array}{l}\text { Lack of high-quality } \\
\text { randomized controlled trials }\end{array}$ \\
\hline Tong Xin Luo [45] & $1995-2005$ & 18 & $\begin{array}{l}\text { Tongxinluo capsule only or } \\
\text { standard treatment plus } \\
\text { tongxinluo capsule vs. } \\
\text { standard treatment or other } \\
\text { anti-angina pectoris drugs, } \\
\text { placebo or no intervention }\end{array}$ & $\begin{array}{l}\text { Unstable angina } \\
\text { pectoris }\end{array}$ & $\begin{array}{l}\text { No affirmative } \\
\text { conclusion }\end{array}$ & $\begin{array}{l}\text { Low methodological quality, } \\
\text { lack of more randomized } \\
\text { controlled trials }\end{array}$ \\
\hline $\begin{array}{l}\text { Puerarin injection } \\
\text { [38] }\end{array}$ & 1995-2004 & 20 & $\begin{array}{l}\text { Puerarin injection vs. } \\
\text { western drugs or placebo; } \\
\text { puerarin injection used with } \\
\text { western drugs vs. western } \\
\text { drugs alone }\end{array}$ & Unstable angina & $\begin{array}{l}\text { Effectiveness in addition } \\
\text { to conventional } \\
\text { treatments }\end{array}$ & $\begin{array}{l}\text { Low methodological quality, } \\
\text { potential publication bias, } \\
\text { lack of more rigorously } \\
\text { designed, randomized, } \\
\text { double-blind, placebo- } \\
\text { controlled trial }\end{array}$ \\
\hline $\begin{array}{l}\text { Compound salvia } \\
\text { pellet [39] }\end{array}$ & 1994-2004 & 27 & $\begin{array}{l}\text { Compound salvia pellet vs. } \\
\text { nitrates }\end{array}$ & $\begin{array}{l}\text { Stable angina } \\
\text { pectoris }\end{array}$ & $\begin{array}{l}\text { Effective on the im- } \\
\text { provement of angina } \\
\text { symptoms and ECG } \\
\text { results with few adverse } \\
\text { events }\end{array}$ & $\begin{array}{l}\text { Low methodological } \\
\text { quality, lack of some } \\
\text { outcome measures }\end{array}$ \\
\hline Shengmai [46] & $1966-2005$ & 19 & $\begin{array}{l}\text { Shengmai + usual treatment } \\
\text { versus usual treatment } \\
\text { alone }\end{array}$ & Heart failure & $\begin{array}{l}\text { No affirmative } \\
\text { conclusion }\end{array}$ & $\begin{array}{l}\text { Low methodological } \\
\text { quality, lack of long-term } \\
\text { and high-quality studies }\end{array}$ \\
\hline $\begin{array}{l}\text { Danqi Piantang } \\
\text { Jiaonang [40] }\end{array}$ & & 2 & $\begin{array}{l}\text { Danqi Piantang Jiaonang } \\
\text { capsules vs. Buchang } \\
\text { Naoxintong Jiaonang }\end{array}$ & Stroke & $\begin{array}{l}\text { Effective on improving } \\
\text { neurological recovery } \\
\text { after stroke }\end{array}$ & $\begin{array}{l}\text { Lack of a large double-blind } \\
\text { randomized clinical trial }\end{array}$ \\
\hline $\begin{array}{l}\text { Maxing Shigan } \\
\text { Decoction [41] }\end{array}$ & $1994-2008$ & 8 & $\begin{array}{l}\text { MXSGD + Western medicine } \\
\text { vs. Western medicine }\end{array}$ & Pneumonia & $\begin{array}{l}\text { Effective on improving } \\
\text { clinical symptoms and } \\
\text { increasing the total ef- } \\
\text { fective rate }\end{array}$ & $\begin{array}{l}\text { Lack of high quality, } \\
\text { multicenter and random- } \\
\text { ized controlled trials with } \\
\text { large-scale design }\end{array}$ \\
\hline $\begin{array}{l}\text { Aidi Injection } \\
\text { [42] }\end{array}$ & $1980-2008$ & 14 & $\begin{array}{l}\text { Aidi Injection + other } \\
\text { treatment vs. other } \\
\text { treatment }\end{array}$ & $\begin{array}{l}\text { Non-small cell } \\
\text { lung cancer }\end{array}$ & $\begin{array}{l}\text { Effective as adjuvant } \\
\text { therapeutic }\end{array}$ & $\begin{array}{l}\text { Small sample size, low } \\
\text { quality, publication bias, } \\
\text { lack of large multicenter } \\
\text { randomized controlled trials }\end{array}$ \\
\hline $\begin{array}{l}\text { Modified xiaoyao } \\
\text { san [43] }\end{array}$ & & 14 & $\begin{array}{l}\text { Modified xiaoyao san or } \\
\text { modified xiaoyao san + } \\
\text { prokinetic drugs vs. } \\
\text { prokinetic drugs }\end{array}$ & $\begin{array}{l}\text { Functional } \\
\text { dyspepsia }\end{array}$ & $\begin{array}{l}\text { Appears to be more ef- } \\
\text { fective compared to } \\
\text { prokinetic drugs }\end{array}$ & $\begin{array}{l}\text { Low methodological quality, } \\
\text { publication bias }\end{array}$ \\
\hline $\begin{array}{l}\text { Kidney-tonifying } \\
\text { and blood- } \\
\text { activating } \\
\text { prescription [47] }\end{array}$ & $1978-2003$ & 35 & $\begin{array}{l}\text { Kidney-tonifying and blood- } \\
\text { activating prescription vs. } \\
\text { Qianliekang or finasteride; } \\
\text { kidney-tonifying and blood- } \\
\text { activating prescription + sur- } \\
\text { gical treatment vs. surgical } \\
\text { treatment }\end{array}$ & $\begin{array}{l}\text { Benign prostatic } \\
\text { hyperplasia }\end{array}$ & $\begin{array}{l}\text { No affirmative } \\
\text { conclusion }\end{array}$ & $\begin{array}{l}\text { Lack of massive, multi- } \\
\text { center and randomized } \\
\text { controlled clinical trial }\end{array}$ \\
\hline
\end{tabular}

using more suitable approaches towards research methods, besides the Cochrane Reviews and paper-based articles.

Because of the unique characteristics of TCM, SRs for TCM efficacy evaluation should focus on a specific subgroup of patients with a specific disease, or a specific herbal preparation with clinically-proven effectiveness. It is also important to address the labeling of the herbal preparation and pay attention to the clarification of intervention and efficacy evaluation. So far, meta-analysis is still a tool for developing recommendations for clinical practice. However, it does have limitations that must be recognized, as the common limitations include bias in the selection of the studies, lack of quality assessment of individual studies, absence of evaluation of heterogeneity among studies (meta-analysis cannot provide satisfactory analyses unless the individual studies are both homogeneous and of sound methodology, this point is very important for TCM studies) and publication bias. Most of the methodological defects of TCM meta-analyses could be supplied if well designed, and meta-analysts should improve the quality of the methodology to maintain the impact on health care. Thus we strongly recommend both improving the quality of the individual clinical trial and paying more attention to the procedures of meta-analyses on clinical trials in TCM. 
Some SRs supported the efficacy of Chinese herbal medicine applications, but few applied rigorous inclusion criteria. Numerous formulas for their treatments and a variety of evaluation criteria as important reasons for limited available comparative evidence do not support one TCM over another for patients. The extent of heterogeneity in many of these RCTs prevented meaningful meta-analysis.

Qualified support for TCM was originally reported in 7 out of 31 SRs. Although many TCM clinical studies carried out in the past 10 years, especially in China, there were relatively few patients in the randomized, double-blinded controlled studies. Only six reviews with more than 200 patients in randomized, doubleblind controlled studies had good evidence of benefit. Despite all this, SRs have overstated the effectiveness by including studies likely to be biased. They provided no robust evidence that TCM works for any indication.

Studies with low methodological quality in which the estimate of quality is incorporated into the meta-analyses can alter the interpretation of the benefit of intervention, whether a scale or component approach is used in the assessment of trial quality. Currently, there are only a few outcomes with adequately supported evidence. More well-conducted, high-quality TCM studies are needed to produce strong evidence for clinical application with good efficacy. At the same time, the methodology and reporting quality are poor, particularly in both SRs and meta-analysis of TCM published in Chinese in the paper-based journals in China. We should respect the need for a high-quality of SRs and metaanalyses, and conduct more quality clinical trials for further SRs and meta-analyses in TCM.

SRs with high quality in TCM efficacy evaluation are needed but they will only be produced through the concerted efforts of clinicians, TCM practitioners and methodologists. The authors suggest that advanced methodological training is necessary for reviewers and financial support is also needed for future systematic reviewing of TCM clinical trials.

In summary, more quality clinical trials of TCM are needed for collecting more evidence to support TCM clinical application.

\section{Randomized Controlled Trials of TCM $\nabla$}

More and more RCTs of TCM have been published in China and abroad in the last decade. They were on a variety of diseases, including 10 types of diseases with TCM pattern classification and 36 kinds of diseases without TCM pattern differentiation.

Most of the results in these RCTs show that TCM is effective in the treatment of diseases or in the alleviation of symptoms, and some state that TCM is not effective or its efficacy is not confirmed. Pattern differentiation of diseases is an essential TCM characteristic and more RCTs on diseases with TCM pattern differentiation were published in recent years ( $\odot$ Fig. 4 ). $\odot$ Fig. 4 indicates an overall increasing trend in RCTs of TCM with pattern classification published from 2002 to 2009 . The figures reached a peak in 2009.

RCTs focused on diseases with TCM pattern classification Ten diseases with pattern differentiation were studied in the 12 RCTs from 2002 to 2009 (@ Table 3). Eleven RCTs showed TCM was effective in the treatment of the diseases or in the alleviation of symptoms; one study failed to confirm the efficacy. No study reported negative results.

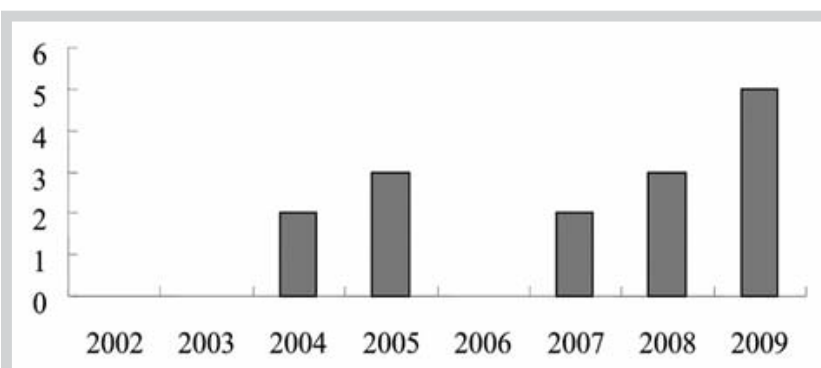

Fig. 4 RCTs of TCM with pattern classification published from 2002 to 2009.

Table 3 RCTs on diseases with TCM pattern classification.

\begin{tabular}{|c|c|}
\hline Diseases & Pattern classification \\
\hline Rheumatoid arthritis [49-51] & $\begin{array}{l}\text { Joint symptoms, cold pattern, } \\
\text { heat pattern, deficiency pattern }\end{array}$ \\
\hline Vitiligo [52] & $\begin{array}{l}\text { Qi-stagnancy and blood-stasis } \\
\text { syndrome type }\end{array}$ \\
\hline Impaired glucose tolerance [53] & Pi-Wei dampness-heat syndrome type \\
\hline Irritable bowel syndrome [54] & Gan-qi attacking Pi syndrome type \\
\hline Unstable angina pectoris [55] & Phlegm and blood stasis syndrome type \\
\hline $\begin{array}{l}\text { Post-traumatic stress disorder } \\
\text { [56] }\end{array}$ & $\begin{array}{l}\text { Heart Shen disturbance Liver Qi } \\
\text { stagnation }\end{array}$ \\
\hline Vascular dementia [57] & $\begin{array}{l}\text { Kidney deficiency and blood } \\
\text { stagnation type }\end{array}$ \\
\hline Gastric ulcer [58] & $\begin{array}{l}\text { Pi-insufficiency and stasis-heat } \\
\text { syndrome type }\end{array}$ \\
\hline $\begin{array}{l}\text { Respiratory syncytial viral } \\
\text { pneumonia [59] }\end{array}$ & $\begin{array}{l}\text { Phlegm-heat blocking Fei syndrome } \\
\text { type }\end{array}$ \\
\hline Bronchial asthma [60] & Qi-deficiency cold syndrome type \\
\hline
\end{tabular}

The RCTs on rheumatoid arthritis studies [49-51] classified three TCM patterns: cold, heat and deficiency patterns. These studies showed that TCM treatment based on pattern classification did affect the efficacy with more symptom relief among the patients. For example, in Shi's study [52], the total effective rate of Zengse pill combined with Western medicine in treating vitiligo patients identified as TCM Qi-stagnancy and blood-stasis pattern (syndrome) was markedly higher than that in the patients treated with Western medicine, and the results showed the therapy can increase the CD4 positive cell and the levels of serum C3 and C4. In a study on impaired glucose tolerance [53], the results showed that giving general knowledge combined with Tang No. 1 granule could be effective for the patient with the Pi-Wei dampness-heat pattern. In a study about the effect of Shugan Jianpi granule in the treatment of irritable bowel syndrome with TCM stagnated Ganqi attacking Pi syndrome type [54], the results showed that Shugan Jianpi granule could regulate the level of 5-HT, and its effect could be enhanced when used in combination with Smecta. On the background of aspirin therapy, Quyu Xiaoban capsules used to treat the patients with unstable angina pectoris with TCM phlegm and a blood stasis pattern significantly attenuated anginal attacks, and improved TCM symptoms and signs [55]. A study on TCM pattern differentiations of post-traumatic stress disorder (PTSD) [56] showed that the most likely TCM patterns for PTSD were heart Shen disturbance, with secondary patterns identified as TCM liver Qi stagnation with liver overacting on spleen/stomach, liver fire, phlegm fire, phlegm-damp, and heart fire and con- 
stitutional deficiencies in the heart, kidney, and spleen organ systems. Liu's study found that Kangxin capsule can effectively improve the symptom of patients with vascular dementia, with TCM senile kidney deficiency and a blood stagnation pattern and the average value of the curative effect index of patients was higher and did not demonstrate any obvious toxic side effect [57]. In a study of gastric ulcer patients with TCM Pi insufficiency and stasis of heat pattern, the curative rate and markedly effective rate in Jianpi Qingre Huayu recipe $(\mathrm{JQH})$ treatment was higher than that in ranitidine therapy, and the abnormal numbers of $\mathrm{CD}^{+}, \mathrm{CD}^{+}, \mathrm{CD} 8+$ cells was restored to the normal range after $\mathrm{JQH}$ treatment and the IL-8 level in gastric mucosa was improved [58]. Yang and coworkers' study on evaluation by survival analysis on the effect of TCM in treating children with respiratory syncytial viral pneumonia with TCM phlegm-heat blocking lung pattern demonstrated that the three curative parameters including comprehensive efficacy, post-treatment main symptoms score improvement and survival analysis of the main symptoms were improved in the TCM treatment [59]. In an RCT on treatment of bronchial asthma with TCM Qi-deficiency and cold pattern by taking Pingchuan Yiqi granule and Ruyi Dingchuan pill [60], the clinically controlled rate, markedly effective rate, improved rate and ineffective rate between the Pingchuan Yiqi granule group and Ruyi Dingchuan pill group showed an insignificant difference, and showed that both TCM preparations were effective in the treatment.

\section{RCTs focused on disease without TCM pattern classification}

There are two kinds of RCTs on diseases without TCM pattern classification: alleviation of symptoms of diseases and on the treatment of diseases. In the past decade, there were about 31 reports on TCM RCTs, including 25 with positive results, 2 with negative results and 4 with non-confirmative results.

As to the RCTs on the alleviation of symptoms, the related symptom alleviations were specifically focused in the study. A study showed that Duhuo Jisheng Wan (DJW) had similar effects in the symptoms alleviation compared to the effects of diclofenac in walking pain, standing pain and stiffness, as well as Lequesne's functional index after 4 weeks of treatment, and the differences were that DJW had a slow action [61]. Two RCTs on acute heroin withdrawal symptoms showed that two TCM therapies including Jinniu capsule and Tai-Kang-Ning could significantly reduce withdrawal symptoms $[62,63]$. In a premenstrual syndrome (PMS) study with placebo control [64], the results showed that TCM had a positive effect on the alleviation of symptoms after three months of treatment. In the treatment of cough in an uncomplicated upper respiratory tract infection RCT study, the results demonstrated that there was no overall statistical significance in the differences of cough score and LCQ (Leicester cough questionnaire) between intervention and placebo groups although both groups had improved in scores [65].

As to the RCTs specific to disease treatment with TCM approaches, the therapeutic effect on the diseases was generally focused. One RA study showed that though there was no significant difference in ACR20 between Ganoderma lucidum, San Miao San combined antirheumatic therapy (biomedicines) and antirheumatic therapy; TCM therapies could remarkably reduce the pain score and diverse effects [66]. The other RCT on RA with an extract of Tripterygium wilfordii Hook F (TwHF) as the treatment showed that the attainment of ACR 20 response criteria was significantly greater with TwHF extract than with sulfasalazine in patients who continued treatment for 24 weeks and could also use stable oral prednisone and nonsteroidal anti-inflammatory drugs; moreover patients receiving TwHF also had significantly higher response rates for ACR 50 and ACR 70 in mixed-model analyses $[67,68]$. In an RCT on unstable angina [68], the results showed that the TCM treatment could decrease the serum TC and LDL-C levels, though it did not change the TG and HDL-C levels. In an RCT about the treatment of patients suffering from nonalcoholic fatty liver with Tiaozhi Yanggan Decoction (TZYGD) [69], the total effective rate of TZYGD was significantly higher than in the control, and more improvements on the symptoms, signs, liver function, blood lipids and iconographic indices were obtained in the TZYGD treated patients. In Jiang's study of Jinye Baidu granule (JYBDG) on fetal growth and development with maternal active human cytomegalovirus (HCMV) infection with a placebo as the control [70], the results showed that JYBDG could produce improvements in the negative conversion rate of both HCMV-lgM and HCMV late mRNA, the positive rate of HCMV-DNA in the placenta and the intrauterine transmission rate, and also reduce the number of infants being born handicapped. An RCT on severe acute pancreatitis (SAP) indicated that Da Cheng Qi Decoction (DCQD) could lower the intra-cystic pressure [71]. In an RCT of chronic hepatitis B, the results showed that He Jie Tang (HJT) could remarkably regulate the unbalanced immune state, and HJT could have a better therapeutic effect if combined with biomedicine therapy [72]. A stratified random sampling trial on hepatitis B virus-related liver cirrhosis showed that TCM therapy could reduce the total bilirubin (TBIL) level and the prothrombin time and increase the fibrinogen level [73]. In an RCT on Shehuang paste navel sticking treating patients with refractory cirrhotic ascites [74], the results showed that the total effective rate of the therapy could reach $84.4 \%$, and the therapy could reduce the blood flow of the portal vein and splenic vein, contents of endotoxin. An RCT on esophageal carcinoma showed that Fuzheng Yiliu granules could improve the erythrocyte immune adherent function when used together with radiotherapy comparing to only radiotherapy application, and suggested the potential role of Fuzheng Yiliu granules in the suppression of invasion and metastasis of malignant cells [75]. The other randomized, double-blind, placebo-controlled study of nasopharyngeal carcinoma demonstrated that Yunzhi-Danshen can exert an immunomodulating effect to lessen the decreases in percentage and absolute count of $\mathrm{T}$ lymphocytes during radiotherapy in nasopharyngeal carcinoma patients [76]. A prospective controlled study on esophageal carcinoma after esophagectomy showed that TCM therapy and TCM therapy combined with biomedical chemotherapy could increase the 1-year, 2-year, 3-year survival rates and improve the quality of life [77]. In an RCT on non-small cell lung cancer, the results showed that the TCM therapy used alone or combination with biomedical therapy could improve the quality of life of tumor patients [78]. Two randomized placebo-controlled clinical trials of asthma showed that symptom scores with asthma were significantly improved with Ding Chuan Tang (DCT) intervention, and DCT could improve the airway hyperresponsiveness $[79,80]$. In an atopic dermatitis study, the results showed that TCM-treated patients had improved children's dermatology life quality index, and could use lower amounts of topical corticosteroid [81]. One RCT on systemic lupus erythematosus reported that TCM therapy for detoxification, removing stasis, and nourishing yin can effectively regulate the levels of fat metabolism to prevent and treat the SLE patients with corticosteroid-induced hyperlipemia [82]. In an RCT with 
shengxueling (SXL) treatment in the patients with refractory idiopathic thrombocytopenic purpura comparison, the results showed SXL had better efficacy and furthermore SXL demonstrated an immediate effect which was obviously superior to that of ampeptide elemente with less adverse effects [83]. An RCT on plaque-type psoriasis treated with TCM demonstrated that the topical application of indigo naturalis ointment could modulate the proliferation and differentiation of keratinocytes in the epidermis, as well as inhibit the infiltration of $\mathrm{T}$ lymphocytes and therefore the subsequent inflammatory reactions in psoriatic lesions [84]. Some RCTs showed negative results or non-confirmed results with TCM therapy. In an RCT on Si Wu Tang (SWT) in the treatment of primary dysmenorrhea, the results showed that SWT did not give a significant benefit to the patients [85]. In the other RCT, the results showed that SWT therapy had no statistically significant improvement in reducing menstrual pain intensity of primary dysmenorrhea at the end of treatment [86]. In an RCT on influenza, the results showed Hochu-ekki-to (HET) did not increase antibody titer after influenza vaccination in man compared to placebo treatment and no adjuvant effects of HET could be found [87]. A study of treatment of diarrhea-predominant irritable bowel syndrome with TCM therapy showed that there was no significant difference in the proportion of patients with global symptom improvement between the TCM and placebo groups at week 8 and at week 16 [88]. An RCT on Chinese herbal medicine (CHM) for reduction of chemotherapy-induced toxicity on breast or colon cancer showed the incidences of grade $3 / 4$ anemia, leukopenia, neutropenia, and thrombocytopenia for the CHM and placebo groups were not significantly different, and CHM does not reduce the hematological toxicity associated with chemotherapy. CHM, however, did have a significant impact on the control of nausea [89]. Like the authors in some RCT reports with negative and non-comfirmed results, we strongly suggest the need for a larger scale study to determine whether the TCM remedy has a role in the treatment of the disease, and furthermore with right selection of patients and herbal preparations.

\section{General clinical observations}

General clinical observations, utilized as retrospective clinical studies, are still common in TCM clinical practice; and there are more reports in TCM clinical studies with general clinical observations instead of application of RCT designed clinical studies. In Chinese journals related to TCM, many reports were found in this category of clinical studies; however, in the database of PubMed, only 11 clinical observations on TCM treating diseases were found, including 10 with positive results and 1 with a negative result.

A study on the effect of Yishen capsule (YSC) in preventing the recurrence of chronic glomerulonephritis demonstrated that YSC had marked effects in decreasing urinary protein [90]. A clinical trial on trilogy detoxicating therapy (TDT) combined with a routine biomedical approach on patients with chronic renal failure showed that TDT had a therapeutic effect [91]. In a clinical observation on the treatment of colon cancer with a combination of chemotherapy and Chinese herbal preparation (Zhao's Weitiao herbal mixture), the data showed that the effect of ZW3 was better in clinical symptom improvement, quality of life improvement, body weight and integral benefit and survival rate [92]. A pilot clinical trial demonstrated that Xilei-san suppository can significantly improve the mean clinical activity index and the endoscopic index of the patients with refractory ulcerative proctitis on the basis of conventional suppositories [93]. In an open- label study of twenty outpatients diagnosed with borderline personality disorder (BPD), patients treated with Yi-gan San showed a statistically significant reduction on self-rated and clinicianrated scales, and the results suggested that Yi-gan San might be effective for the treatment of a number of BPD symptoms, including low mood, impulsivity, and aggression [94]. A study of 59 patients with age-related mild cognitive impairment of the nonAlzheimer type treated with Ginkgo biloba extract showed that the SF-12 mental score of the patients had increased significantly and about half of all patients experienced an improvement in their memory and their ability to concentrate, as well as a decrease in symptoms of forgetfulness [95]. A study of SWT treating dysmenorrhea indicated a decrease in menstrual pain levels and the duration of pain [96]. A trial of Weicao capsule in treating gout showed that the total effective rate was $87 \%$ in Weicao capsule treatment, which was superior to that in a Tongfengding capsule group [97]. A clinical observation on YiSuiShengXue granule treating 156 patients with beta-thalassemia indicated that the granule had a total effective rate of $92.9 \%$ and produced no obvious adverse reactions [98]. A study on hemophilia showed that the short-term markedly effective rate in the patients treated with Xueyou mixture was up to 95.38\% [99]. Although the clinical observations are not well designed, they can provide preliminary data and recommendations for further clinical application.

\section{Summary and comments}

Pattern differentiation is specific to TCM. RCTs should be conducted based on TCM pattern differentiation and modern disease classifications. Increasing number of RCTs of TCM has been designed with TCM pattern differentiation; however, the quality of the RCTs is far from being satisfactory.

Most RCTs of TCM with pattern differentiation were of low quality. More multicenter and long-term trials are needed for verifying the efficacy of TCM in the treatment of diseases with pattern differentiation.

The results in the RCT on rheumatoid arthritis showed that symptoms combination could coincide with TCM pattern differentiation [1-3]. Also there are some TCM patterns differentiated in a specified disease, and it might be more effective to conduct the RCT which involves not only one single TCM pattern but more TCM patterns treated with corresponding TCM therapies.

In the future, RCTs of TCM with pattern classification should be launched in order to observe treatment effects of one or a few medicines for different syndromes of a disease. Another tendency in TCM RCTs is that an increasing number of scientists use integrative approaches (TCM combined with Western medicine) as intervention and apply system biology as a mechanism explanation approaches.

In RCTs on diseases with TCM therapy and without TCM pattern differentiation in the disease, some questions should be addressed. To assess the efficacy of inclusion of TCM in treatment, the stratification of patients with the TCM pattern should be the key issue in conducting RCTs for TCM therapy. Also in some specific diseases, TCM therapy might be helpful in alleviation of the symptoms. This field should be addressed with TCM pattern differentiation when TCM is included as part of the treatment.

Owing to the diversity of TCM compositions, choosing the right herbal preparation becomes another important issue in the TCM-related RCT. We recommend taking the primarily proved herbal preparations in the efficacy evaluation. Although most re- 
sults in the RCTs are positive, the quality of most of the RCTs is low.

General clinical observations, although with not well-designed protocols, could provide some data to support future RCTs or recommendations for clinical application. The authors suggest that RCTs of TCM could be better conducted in collaboration with TCM doctors who have full experience in general clinical observation.

\section{General Issues and Suggestions}

The history of clinical trials can be dated back to approximately 600 B.C. [100], and various types of clinical trials have been developed ever since. Clinical trials can be classified by the aspects of intervention that investigators want to explore, the way in which the participants are exposed to the intervention, the number of participants included in the study, whether the investigators and participants know which intervention is being assessed, and whether the preference of non-randomized individuals and participants has been taken into account in the design of the study [101-103].

In the hierarchy of evidence that influences health care policy and practice, RCTs are considered as the top individual unit of research and the most reliable form of scientific evidence, as they might eliminate the spurious causality and bias [101]. RCTs involve the random allocation of different interventions (treatments or conditions) to subjects. As long as the number of subjects is sufficient, randomization is an effective method for balancing confounding factors between different interventional groups [102].

TCM has a long history but its efficacy is not as well documented as one would hope. Proof of efficacy has to come from empirical researches, i.e., clinical trials, prospective experiments assessing the effects of medical interventions. In TCM, an increasing number of RCTs are being conducted. Generally, the design and reporting of clinical trials of TCM should follow the same guidelines as those for any other such research. However, there are still some general issues in TCM clinical trials which should be addressed.

\section{Randomization}

The methods of allocation in studies described as randomized are poorly and infrequently reported $[103,104]$, as illustrated in a study of 206 RCTs, although randomization was included as one of the main design features necessary to prevent bias, it was poorly reported [105].

As a result, it is not possible to determine, on most occasions, whether the investigators used proper methods to generate random sequences of allocation [103]. In reviewing an initial sample of 37313 articles from the China National Knowledge Infrastructure electronic database, reports of RCTs were searched on 20 common diseases published from January of 1994 to June of 2005. RCTs published in some Chinese journals lacked an adequate description of randomization, and similarly, most so-called "randomized controlled trials" were not real randomized controlled trials owing to a lack of adequate understanding on the part of the authors of the stringent clinical trial design [106].

\section{Inclusion of control groups}

In an RCT, the importance of having a control group cannot be overstated. To have a proper design of the control group is one of the key factors in an RCT for TCM therapy. A review of 66 RCTs with Chinese herbal medicines for type 2 diabetes mellitus in July 2005 showed that a variety of control groups was used, including placebo, positive and waiting-list control groups [107].

However, extant control strategies may not be appropriate for RCTs of TCM. In many RCTs of TCM, a positive control, which employs a conventional medicine with strong evidence of efficacy, is used widely to confirm the efficacy of TCM treatment. Most results concluded by such kinds of RCTs proved that conventional drugs had better efficacy than TCM when a single disease or symptom was employed as the evaluation criteria. However, the effect based on a TCM pattern was not publicly regarded and validated, as the outcome measures lack adequate accounting for multiple statistical tests and evidence. Furthermore, conventional drugs always have more definite mechanisms with a single target and treatment indication, but TCM acts in a more complicated, network-like way so that its indication is often made up of a group of symptoms/patterns rather than a single disease or symptom. Thus the efficacy measurement between the two kinds of medicines is difficult to be notarized for the validity.

Approved or well-used Chinese medicines are also included as control groups in certain trials. In such cases, both therapeutic regimens had complex active mechanisms. Nevertheless, even if the indication of the two regimens proved to be the same pattern in TCM, different Chinese medicines might have diverse biological parameters/targets, which would have influenced the comparing measurement of efficacy and lead to false assessment. It is difficult to design a perfect placebo on account of the special taste and appearance of the Chinese herbal medicines. The blindness would be revealed ahead of trial schedule by the improper placebo. Also the ethical requirements would limit the usage of a placebo in many cases.

In summary, different control groups may be appropriate according to the study objectives, and several factors should be considered prior to selecting control groups in future RCTs of Chinese herbal medicines [107]: (i) control groups for RCTs should be selected according to study objectives; (ii) interventions as positive control groups should have the strongest evidence of efficacy with prescriptions as recommended by TCM practitioners, and act in similar ways as the test intervention; (iii) placebo should bear the physical characteristics of tested medications as closely as possible and be completely inert; (iv) no treatment control groups should be used when withholding treatment is ethical and objective outcomes will not be subject to bias due to absent blinding; and (v) registration through the Chinese Clinical Trial Registry (CHICTR) and getting open access to information about ongoing and completed trials will help in designing the proper control strategies.

Innovative control group strategies which would meet the characteristics of RCTs in TCM are still needed, with the interdisciplinary support of data from medicine, pharmacology, pathology, pharmacokinetics, pharmaceutics, and other appropriate information of the products.

\section{TCM pattern classification}

Utilizing a diagnostic approach in TCM, pattern classification is applied to stratify the patients and make more suitable indications for inclusion criteria in RCTs. However, one of the most important problems which decreases the acceptance of RCTs in TCM 
is the absence of standard TCM diagnosis criteria during patient recruitment.

In some RCT designs, patients with the same disease were recruited and received TCM or conventional treatment, respectively, but the information for TCM pattern classification was ignored. In these studies, conventional treatment tends to produce a better curative effect than TCM, the RCT failed to evaluate the real efficacy of TCM.

If the patients were given different TCM treatments according to their pattern diagnosis in TCM, the results may show that it is efficacious, but to generalize the success of treatment efficacy is difficult unless the trial is sufficiently large to allow subgroup analyses. On the other hand, if patients with the same TCM pattern diagnosis can be recruited from those with a particular disease in conventional medicine in a trial, the same TCM treatment can be evaluated, and generalization about the therapy would be valid, but eligible patients available for such a study could be small in number and difficult to recruit.

Increasing numbers of medical researchers recognize that the combination of disease diagnosis in biomedicine and pattern classification in TCM is essential for the clinical practice when TCM is included as part of the treatment alongside conventional medical approaches, and it has been a common practice model in China since it may produce a better clinical effect [108]. Therefore, defining TCM pattern classification becomes the underlying issue of TCM RCTs. Before an RCT is conducted, there should be standard criteria for pattern classification of the targeted disease with the support of acceptable data and evidence.

Since pattern classification is mainly based on symptoms (including self-reported signs), tongue and pulse diagnosis, it is difficult to be understood by Western medicine researchers. The symptoms, tongue and pulse diagnosis are often diversified. Some of them, not closely related to the disease diagnostic parameters, are less focused upon by modern medicine, such as thirst and turbid urine and yellow tongue fur in some diseases [109]. Although symptoms are diversified in a disease, they can be clustered into specific groups with biostatistical approaches, even though traditionally they are classified into groups based on TCM theory and clinical experiences. A multicenter RCT study has shown that among 8 common symptoms of RA, 5 are related to the joint, and 3 are not related to the joint. Symptoms clusters in 396 patients could be classified into 4 factors (symptom combinations) with factor analysis. The symptom combinations are very similar to the patterns differentiated by TCM theory in RA patients, which divides RA into three basic patterns: cold, heat and deficiency patterns [51].

TCM patterns in a disease, such as RA, might have biological basis in the view of biomedical sciences. The gene profile differences between the cold and heat patterns of RA patients might mainly refer to the amino acid and fat metabolism [110]. Another research on chronic gastritis shows that the TCM symptom groups in chronic gastritis was positively correlated with gastric mucosal immune reactions [111].

Based on the TCM pattern classification, the severe cartilage erosion in the later stages of RA patients was regarded as the blood stasis and deficiency pattern in TCM. It was proven that blood stasis and deficiency patterns in TCM were related to blood rheology and immune regulation [112]. Thus, it is reasonable to make the hypothesis about positive relationships among $\operatorname{IgA}$, platelet and cartilage erosion. The changes in the peripheral IgA level and platelet number positively correlated with the grade of carti- lage damage in active RA patients which supported the hypothesis $[113,114]$.

Thus the application of TCM pattern classification would also be helpful to find the innovative therapeutic methods. More importantly, pattern classification will help improve the clinical efficacy in clinical practice since it further specifies the indication with TCM classification. A clinical research shows that better effective treatment rate could be achieved from the RA patients with some specific symptoms and the results suggest that RA patients should be treated differently based on their pattern differentiation [51].

Above all, pattern classification based on TCM information such as symptoms is important for further stratification of disease, which will help improve the clinical practice in the treatment of disease with further specified indication of the therapy and the validity of RCTs in TCM. The idea of integrating pattern classification with disease diagnosis might be helpful in making innovations in modern clinical research, not only for TCM studies [2].

\section{Quailty of Life (QOL), Patient Reported Outcomes (PROs) and Biomarkers \\ $\nabla$}

It is acceptable that quality of life (QOL) indicators are often used as secondary outcome indicators in many clinical studies. However, the efficacy of TCM on QOL has not been particularly evident in these studies. There is a general impression among TCM practitioners that the currently available QOL instruments may not be sensitive enough to detect the health changes that are regarded as important in treatment using TCM. For example, in TCM diagnosis and treatment regimes, appetite and digestion, routine of urination and stools, facial and lip color, lutre in the eyes and adaptation to climates and seasons are very important indicators of health status. However, these indicators are usually not included in common health-related QOL (HRQOL) measures. Through the development of Chinese medicine-based QOL (ChQOL) [115] we demonstrated this evidence-based approach using patient-reported outcomes or HRQOL measures can be utilized to evaluate treatment efficacy of Chinese medicine, and thereby build a bridge for the integration of Chinese medicine into mainstream health care [116].

Patient-reported outcomes (PROs), generated from QOL instruments administered to patients before and after treatment intervention, refer to self-reported outcomes in the context of health care, and include any report generated directly from the person or persons involved. PROs include not only health status and quality of life but also report on the satisfaction with the treatment and care, the adherence to prescribed regimens when directly related to end-result outcomes, and any other treatment or outcome evaluation obtained directly from the patients through interviews, self-completed questionnaires, diaries or other data collection tools, such as hand-held devices and webbased forms [117].

PROs and HRQOL are self-reported outcomes in the context of health care. They are essential endpoints in any clinical trial in which the patient's self-report is the primary or sole indicator of the disease activity; as well as when the treatment has a small impact on survival but may have a significant impact, positive or negative, on HRQOL; the treatment may adversely affect a patient's ability to function and their well-being; the treatment aims to offer equal clinical efficacy but differential PRO benefits; and treatment-related decisions are based on a combination of 
objective and patient-reported subjective parameters [118]. The Food and Drug Administration (FDA) proposed the term "patient-reported outcomes" to represent these types of patientbased assessments in the regulatory review process [119]. In fact, PRO is not new in CM practice. The PRO concept is actually similar to one of the four diagnostic methods in TCM: "interrogation", which has been used since the beginning of TCM, and is a very effective diagnostic and evaluation method in TCM.

The fact that the FDA adopts the inclusion of PROs in clinical trial studies of new drug development may indicate indirectly that the diagnostic and evaluation methods used in TCM can be used as efficacy measurement indices in addition to RCT approaches. Another useful direction of using PROs could be that pragmatic PRO studies will also provide theoretical and practical insights into the usefulness of the TCM theory and TCM-based therapies. In debates about modernization of TCM in the past century, some people felt that it was possible to abandon the TCM theory but retain Chinese materia medica (CMM) for development of new medicines. History shows that all these attempts ended with little success. TCM theory and CMM are integral parts of Chinese medical practice. Without TCM theory for diagnosis and treatment, the CMM will lose direction in its applications. CM theories are very crucial in ensuring the proper application, in terms of efficacy and safety, of CMM in treating diseases and saving lives [116]. The mere phytochemical separation of CMM in the hope of discovering new chemical entities has not produced many compounds leading to the production of new pharmaceuticals [120].

Treatment-related decisions are based on a combination of objective and subjective parameters as well as PROs. Monitoring endogenous biomarkers in relation to healthy and disease conditions is an objective measurement. Biomarkers are molecular biological or physical characteristics that are used to identify risk for disease, and also to diagnose and treat a disease. Cholesterol, blood sugar, proteins and genes are some examples of biomarkers. Monitoring clinical biomarkers is an emerging strategy in the future development of conventional medicine to formulate individualized or stratified medicine [121]. We demonstrated that, after strict product quality control before commencement of clinical studies, it was feasible to adopt a protocol including administration of an HRQOL instrument such as ChQOL to monitor PROs and with the measurement of objective biomarkers such as insulin-growth hormone factor 1 (IGF-1) and homocysteine before and after administration of TCM products in patients with allergic rhinitis [122], developing metabolic syndrome [123], suffering from hepatitis B, [124] and in healthy volunteers [125]. Although efficacy was shown, these RCT studies included only small number of subjects. But the results encourage further development of the products for multiple-center trials or submission for preregistration of the products to regulatory agencies. Nevertheless the principles of adopting both objective (monitoring biomarkers and PROs) and subjective parameters (data recorded by practitioners) in assessment efficacy of TCM treatment should be encouraged for future approaches.

\section{Quality control}

Most RCT studies of TCM have more methodological limitations than conventional medicine according to some reports [126], although increasing attention has been paid to quality control. Many differences exist between clinical trials of TCM and conventional medicine [127]. To confirm the patient's compliance to TCM treatment is a critical problem especially in the West be- cause of the absence of Chinese cultural influence on the patient population. TCM treatment requires a long cycle in clinical trials, because herbal medicine apparently is milder in action and takes a relatively long time to manifest itself clinically. This means that trials must involve larger patient numbers and longer study periods than those of conventional medicine. It is likely that the dropout rate would increase, and may affect the final statistical analysis and the credibility of the trial. It is also difficult for a Western physician to fully understand and fulfil a clinical trial design in TCM. In a large sampled, multicentral RCT, it is challenging to organize a large-scale clinical research team.

In addition to these general difficulties, clinical trials of TCM encounter a range of problems that are not unique to TCM but, in terms of their size, represent more specific obstacles to research [127].

Many RCTs are limited by small sample sizes or inconsistencies in the TCM preparations studied [126]. In some RCTs, the study populations differed considerably from typical primary care populations, and participants were not always screened to rule out other possible causes of their symptoms. An analysis of data on methodological quality of RCTs from 414 full length articles before 1 January 1997 in the Chinese Journal of Integrated Traditional and Western Medicine showed that only a few studies had sample sizes of 300 subjects or more [6].

Complementary medicine journals likely to publish articles on TCM are associated with a strong positive publication bias [128]. The concern therefore is that, due to a range of factors, bias is more of an issue in TCM than in conventional medicine.

In TCM trials, soft and non-validated outcome measures are often employed, e.g., percentage of patients perceiving benefit or patients' preference. Similarly, multiple outcomes are frequently used without adequately accounting for multiple statistical tests. Finally, surrogate endpoints are frequent and researchers often seem to measure what is measurable rather than what is relevant.

Double blindness as a prerequisite criterion can be difficult to achieve because of the taste, odor or appearance of herbal medicines that could not be distinguished from their respective placebos as exemplified by the numerous "placebo-controlled, doubleblind" trials of garlic preparations for cholesterol lowering [129]; due to the body odor caused by garlic, blinding is not a realistic option. Likewise double-blind studies in clinical trials of acupuncture possess a significant problem. In the foresaid analysis, it was found out that blinding was used in only $15 \%$ of the trials [6]. Quality control and safety issues of CMM preparations or composites formulae in the form of PCM should be a prerequisite criterion before commencement of clinical trials due to the variability of compositions and sources of origin of crude materials.

Most problems related to RCTs of TCM can be solved. At present, the government in China has increased the funding and technology inputs for clinical research of TCM to establish an effective system of quality control and standardization for the process of RCTs, such as training and communication. For example, the above 50 ongoing research projects supported by the National Key Technology R \& D Program carried out RCTs with registration, and the design of every project was optimized by relevant experts, and the whole trials are supervised under a 4-class audit system with the support by an internet management center which can implement real-time data input and transmission. These measures would undoubtedly promote the quality of RCTs in TCM. More worldwide communication and collaboration with multi-field experts will also benefit the quality of RCTs in TCM. 
On the whole, we strongly recommend that the TCM clinical trials should be conducted in a well designed and strictly quality controlled way in order to show the efficacy of TCM, though the clinical trials will involve some key characteristics of diagnosis and therapy.

\section{Safety evaluation}

Clinical trials are used not only to establish efficacy of an intervention but also to learn its most frequently occurring side effects. So the report and analysis of adverse drug reactions (ADRs)/ adverse events should be another focus in the outcomes. However, there seemed to be underreported adverse events in some RCTs [126], especially in trials of TCM, as Chinese herbal medicines were always considered as natural and thus safe products.

It is important to realize that personal experience is not a reliable basis for the exclusion of uncommon reactions to herbal remedies [130]. On the other hand, ADRs might have some correlation with the efficacy, or sometimes can be a predictive factor for the therapeutic effect in TCM clinical practice. In a multicenter, randomized clinical trial which was conducted on 505 RA patients in China [131], after 12 and 24 weeks of treatment, the efficacy and safety of Western medicine therapy and Chinese medicine therapy were analyzed and compared.

The researchers found that gastrointestinal (GI) ADRs was inversely correlated with efficacy in conventional biomedical therapy in the treatment of RA, and the correlation could not be observed in the RA patients treated with Chinese medicines. Some correlative regularity between ADR development and the medication time can be obtained, with ADRs as the exceptional and inevitable outputs of drug action $[132,133]$. There are some researches on the development of a predictive model of the drug responses in complex diseases in order to find a new way of individualized treatment [134]. The results suggest that it could be sensible for clinicians and researchers to pay more attention to ADRs both for side effects and for the prediction of effectiveness.

\section{Case study in TCM}

An often-voiced criticism of clinical trials is that such clinical experiments tell us little about progress of individual patients after treatment intervention. In TCM, treatments are often highly individualized. Although the importance of the case study has been widely recognized, the quality of the case reporting in TCM is still unsatisfactory.

As one of the primary methods of knowledge transmission in $\mathrm{TCM}$, the case report played a critical role in the history. It is embedded in Chinese culture with its unique characteristics of focusing on key information for pattern classification without the efficacy evaluation criteria provided, which has resulted in difficulty in acceptance and comprehension by the modern medical system.

In the case report of modern medicine, more emphasis is put on record of the discussion over the diagnosis of complex diseases, or the treatment of rare cases. Every case report/record contains the complete medical record in detail including diagnosis and efficacy evaluation. Presently, most TCM case reports failed to meet the criteria of an optimal case study to provide high-level evidence for follow-up research studies. Therefore, it is of paramount urgency that in TCM practice the procedure for reporting case studies should be standardized and established with a common language that can be communicated with modern conventional medicine for comparison of treatment efficacy and evidence-based discussion.
The current priority is the standardization of clinical terminology and record format, with definitive and adequate information for diagnosis and efficacy evaluation. To encourage the utilization of the case report as a means of an evidence-based approach for assessment of TCM treatment efficacy, further analysis using modern information processing technology of well-kept data in TCM treatment of common diseases will contribute to the optimization of the TCM treatment strategy and promote the development of individualized treatment with TCM.

The quality of case-reporting in TCM can also be improved by taking the strict measure/procedure developed by the National Cancer Institute (NCI) in the USA, whose current key role is committed to funding innovative treatment in cancer research by providing funding via the NCl's Office of Cancer Complementary and Alternative Medicine (OCCAM) which coordinates the institute's research programs of complementary and alternative medicine (CAM).

The NCI procedure, known as the NCI Best Case Series (BCS) Program, evaluates data from CAM practitioners that involve the same rigorous scientific methods employed in evaluating treatment with conventional medicine. This procedure provides an independent review of medical records and medical imaging from patients treated with unconventional cancer therapies. Its primary goal is to obtain and review sufficient information to determine if $\mathrm{NCI}$-initiated research on a specific intervention is warranted [http://www.cancer.gov/cam/bestcase_intro.html]. Some criteria also meet the needs of the TCM case report, thus following the BCS program standard can be adopted to the improvement of reporting quality in the TCM case-study reporting. Such an approach can be utilized to provide evidence-base validation for TCM treatment efficacy.

\section{Conclusions and Perspectives}

Over the last decade, we have observed increasing numbers of clinical trials on TCM treatment efficacy and we predict that there will be more RCTs with higher quality in the future to meet the needs of modern research and development, and that the quality of RCTs will be improved with the generalized RCT registration, standardization of clinical research, and the promotion of evidence-based medicine (EBM).

TCM pattern classification will be incorporated into research design, producing value-added clinical evidence to prove the efficacy of TCM based on its own diagnostic and treatment principles. The innovative design of an RCT with integrating pattern information and disease diagnosis for group classification will certainly explore more valuable contributions of TCM treatment and can avoid the shortages of some study designs in assessing TCM efficacy that utilize Western medical research methods without discriminating patterns that are unique characteristics and the essence of the TCM diagnosis and treatment theory.

Meta-analysis as a high-class evidence would increase as there will be increasing amounts of high-level, high-quality data to support the systematic review. A leap forward of meta-analysis/ systematic reviews on TCM should be expected. Increasing acceptance of Chinese herbal medicine, acupuncture and massage therapy will contribute more to human health care with their involvement in the global health management system. Such an increase in acceptance also offers the research opportunity for wider study of TCM efficacy worldwide. 
In the not too distant future, researchers will find a new approach for recording case-study reports to include valuable patient and medical information. Recently in our RCT panel studies of TCM formulated products [122-125] we demonstrated that monitoring biomarkers and PROs/ChQOL before and after intervention with these products can assess efficacy of the TCM products. Both conventional medical and TCM characteristics of the patient/volunteer can be compared to provide data for assessment. These approaches integrate both conventional medical assessment methods and TCM diagnosis and treatment principles in the form of ChQOL/PROs [116].

The opportunity of recording objective and subjective outcome indicators such as biomarkers, PROs and HRQOL, and TCM practitioners' treatment records, respectively, can also be applied to the evidence-based approaches for assessing TCM treatment efficacy on individual patient cases. Such integrative approaches utilize the superiorities of both modern case reports used in conventional medicine with TCM recording methodology. The evidence level of the case study will be improved and ascertained by applying innovative analysis with modern information processing technologies. These new approaches will be more suitable for case study and may pave the way for ascertaining TCM principles of holistic approaches to diagnosis and treatment of diseases and individualized treatment for patients.

In summary, the worldwide focus on clinical trials in TCM will continue to increase. Researchers both in basic and clinical sciences will need to consider universally accepted standardized operating procedures (SOP) for clinical assessment of TCM treatment efficacy and in clinical trials of TCM products agreeable in general with TCM principles and acceptable to regulatory agencies. We have given suggestions in several key areas in the abovementioned sections addressing global acceptance and recognition of both quantity and quality in clinical studies of TCM, development of innovative modifications of the standard design of clinical trials as well as focusing on specific research questions and proposed solution encountered in TCM treatment principles.

\section{Acknowledgements}

\section{$\nabla$}

This research is partly sponsored by the projects from the National Science Foundation of China (Project No.30825047 and 90709007) and National Eleventh Five Year Support Plan (Project No. 2006BAI04A10).

\section{References}

1 Nestler G. Traditional Chinese medicine. Med Clin North Am 2002; 86: 63-73

$2 \mathrm{Lu} A P$, Chen $\mathrm{KJ}$. Integrative medicine in clinical practice: from pattern differentiation in traditional Chinese medicine to disease treatment. Chin J Integr Med 2009; 15: 152

3 Davies HD, Crombie IK. What is a systematic review? Evid Based Med 2001; $1: 1-6$

4 Hannes $K, W u$ T. Science in progress: filling in the blanks with systematic reviews. Zhongguo Xun Zheng Yi Xue Za Zhi 2007; 7: 827-829

5 Lai SL. Developing systematic review of clinical medical documents of TCM. Zhongguo Zhong Yi Yao Xin Xi Za Zhi 2000; 7: 78

6 Tang JL, Zhan SY, Ernst E. Review of randomised controlled trials of traditional Chinese medicine. BMJ 1999; 319: 160-161

7 Zhang WB, Jiang HL, Zhou W, Zhong YQ Yang HM, Fu JJ, Mao B. Chinese medicine for acute upper respiratory tract infection: a systematic review of randomized controlled trials. Zhong Xi Yi Jie He Xue Bao 2009; 7: 706-716
8 Zhang MM, Liu XM, He L. Effect of integrated traditional Chinese and Western medicine on SARS: a review of clinical evidence. World J Gastroenterol 2004; 10: 3500-3505

9 Tu X, Huang G, Tan S. Chinese herbal medicine for dysfunctional uterine bleeding: a meta-analysis. Evid Based Complement Alternat Med 2009; 6: 99-105

10 Zhu X, Proctor M, Bensoussan A, Wu E, Smith CA. Chinese herbal medicine for primary dysmenorrhoea. Cochrane Database Syst Rev 2008; 2 : CD005288

11 Rathbone J, Zhang L, Zhang M, Xia J, Liu X, Yang Y. Chinese herbal medicine for schizophrenia. Cochrane Database Syst Rev 2005; 4: CD003444

12 May BH, Lit M, Xue CC, Yang AW, Zhang AL, Owens MD, Head R, Cobiac L, Li CG, Hugel H, Story DF. Herbal medicine for dementia: a systematic review. Phytother Res 2009; 23: 447-459

13 May BH, Yang AW, Zhang AL, Owens MD, Bennett L, Head R, Cobiac L, Li $C G$, Hugel $H$, Story DF, Xue CC. Chinese herbal medicine for mild cognitive impairment and age associated memory impairment: a review of randomised controlled trials. Biogerontology 2009; 10: 109-123

14 Lan Y, Zhang LL, Luo R. Attention deficit hyperactivity disorder in children: comparative efficacy of traditional Chinese medicine and methylphenidate. J Int Med Res 2009; 37: 939-948

15 Flower A, Liu JP, Chen S, Lewith G, Little P. Chinese herbal medicine for endometriosis. Cochrane Database Syst Rev 2009; 3: CD006568

16 Cho WC, Chen HY. Clinical efficacy of traditional Chinese medicine as a concomitant therapy for nasopharyngeal carcinoma: a systematic review and meta-analysis. Cancer Invest 2009; 27: 334-344

17 Meng MB, Cui YL, Guan YS, Ying Z, Zheng MH, Yuan CK, Zhang RM. Traditional Chinese medicine plus transcatheter arterial chemoembolization for unresectable hepatocellular carcinoma. J Altern Complement Med 2008; 14: 1027-1042

18 Xu L, Lao LX, Ge A, Yu S, Li J, Mansky PJ. Chinese herbal medicine for cancer pain. Integr Cancer Ther 2007; 6: 208-234

19 Bai SL, Hu XY, Zhong S. Evaluation on HBeAg conversion time when treating chronic hepatitis $B$ patients with combination of lamivudine and traditional Chinese medicine. Zhonghua Liu Xing Bing Xue Za Zhi 2008; 29: 1243-1247

20 McCulloch M, Broffman M, Gao J, Colford Jr JM. Chinese herbal medicine and interferon in the treatment of chronic hepatitis B: a meta-analysis of randomized, controlled trials. Am J Public Health 2002; 92: 16191628

21 Chen X, Wu T, Liu G. Chinese medicinal herbs for influenza: a systematic review. J Altern Complement Med 2006; 12: 171-180

22 Liu JP, Manheimer E, Shi Y. Systematic review and meta-analysis on the integrative traditional Chinese and Western medicine in treating SARS. Zhongguo Zhong Xi Yi Jie He Za Zhi 2005; 25: 1082-1088

23 Liu JP, Zhang M, Wang WY, Grimsgaard S. Chinese herbal medicines for type 2 diabetes mellitus. Cochrane Database Syst Rev 2004; 3: CD003642

24 Wu B, Liu M, Liu H, Li W, Tan S, Zhang S, Fang Y. Meta-analysis of traditional Chinese patent medicine for ischemic stroke. Stroke 2007; 38 : 1973-1979

25 Qiong W, Yiping W, Jinlin Y, Tao G, Zhen G, Pengcheng Z. Chinese medicinal herbs for acute pancreatitis. Cochrane Database Syst Rev 2005; 1 : CD003631

26 Chen JX, Hu LS. Traditional Chinese medicine for the treatment of chronic prostatitis in China: a systematic review and meta-analysis. J Altern Complement Med 2006; 12: 763-769

27 Chi JF, Niu JZ, Xu SQ Li J, Wang JF, Liu JP. Treatment of Alzheimer disease: an evidence-based review. Zhong Xi Yi Jie He Xue Bao 2007; 5: 247254

28 Yang ZM, Tang XJ, Lao YR. Systematic evaluation on clinical literature related with treatment of Parkinson's disease with traditional Chinese medicine. Zhongguo Zhong Xi Yi Jie He Za Zhi 2005; 25: 612-615

29 Szczurko O, Boon HS. A systematic review of natural health product treatment for vitiligo. BMC Dermatol 2008; 8: 2

30 Jing $Z$, Yang $X$, Ismail $K M$, Chen $X, W u T$. Chinese herbal medicine for premenstrual syndrome. Cochrane Database Syst Rev 2009; 1: CD006414

31 Dengfeng W, Taixiang W, Lina H, Marjoribanks J, Guanjian L, Haijun J, Ying S, Jing Z. Chinese herbal medicines in the treatment of ectopic pregnancy. Cochrane Database Syst Rev 2007; 4: CD006224 
32 Zen XX, Yuan Y, Liu Y, Wu TX, Han S. Chinese herbal medicines for hyperthyroidism. Cochrane Database Syst Rev 2007; 2: CD005450

33 Wei X, Chen CZ, Wu T, Yang X, Liu G. WITHDRAWN: Medicinal herbs for esophageal cancer. Cochrane Database Syst Rev 2007; 4: CD004520

34 Lin J, Huang WW. A systematic review of treating Helicobacter pylori infection with Traditional Chinese Medicine. World J Gastroenterol 2009; 15: 4715-4719

35 Cameron M, Gagnier JJ, Little CV, Parsons TJ, Blumle A, Chrubasik S. Evidence of effectiveness of herbal medicinal products in the treatment of arthritis. Part 2: Rheumatoid arthritis. Phytother Res 2009; 23: 16471662

$36 \mathrm{Li}$ Q Chen X, He L, Zhou D. Traditional Chinese medicine for epilepsy. Cochrane Database Syst Rev 2009; 3: CD006454

37 Junhua Z, Menniti-Ippolito F, Xiumei G, Firenzuoli F, Boli Z, Massari M, Hongcai S, Yuhong H, Ferrelli R, Limin H, Fauci A, Guerra R, Raschetti R. Complex traditional Chinese medicine for poststroke motor dysfunction: a systematic review. Stroke 2009; 40: 2797-2804

38 Wang $Q$, Wu T, Chen X, Ni J, Duan X, Zheng J, Qiao J, Zhou L, Wei J. Puerarin injection for unstable angina pectoris. Cochrane Database Syst Rev 2006; 3: CD004196

39 Wang G, Wang L, Xiong ZY, Mao B, Li TQ. Compound salvia pellet, a traditional Chinese medicine, for the treatment of chronic stable angina pectoris compared with nitrates: a meta-analysis. Med Sci Monit 2006; 12: SR1-SR7

40 Chen C, Venketasubramanian N, Gan RN, Lambert C, Picard D, Chan BP, Chan E, Bousser MG, Xuemin S. Danqi Piantang Jiaonang (DJ), a traditional Chinese medicine, in poststroke recovery. Stroke 2009; 40: 859-863

41 Li L, Lu FG, He QH. Efficacy of Maxing Shigan Decoction combined with Western medicine for pneumonia in children: a systematic review and meta-analysis. Zhong Xi Yi Jie He Xue Bao 2009; 7: 809-813

42 Ma WH, Duan KN, Feng $M$, She B, Chen $Y$, Zhang RM. Aidi injection as an adjunct therapy for non-small cell lung cancer: a systematic review. Zhong Xi Yi Jie He Xue Bao 2009; 7: 315-324

43 Qin F, Huang X, Ren P. Chinese herbal medicine modified xiaoyao san for functional dyspepsia: meta-analysis of randomized controlled trials. J Gastroenterol Hepatol 2009; 24: 1320-1325

44 Wu B, Liu M, Zhang S. Dan Shen agents for acute ischaemic stroke. Cochrane Database Syst Rev 2007; 2: CD004295

$45 \mathrm{Wu} T$, Harrison RA, Chen X, Ni J, Zhou L, Qiao J, Wang Q Wei J, Xin D, Zheng J. Tongxinluo (Tong xin luo or Tong-xin-luo) capsule for unstable angina pectoris. Cochrane Database Syst Rev 2006; 4: CD004474

46 Chen J, Wu G, Li S, Yu T, Xie Y, Zhou L, Wang L. Shengmai (a traditional Chinese herbal medicine) for heart failure. Cochrane Database Syst Rev 2007; 4: CD005052

47 Wang L, Zhou S, Shao J, Zhang S. System review of the Chinese medicine bushenhuoxue for treating benign prostatic hyperplasia. Zhonghua Nan Ke Xue 2004; 10: 785-789

$48 \mathrm{Yu}$ S, Zhong B, Zheng M, Xiao F, Dong Z, Zhang H. The quality of randomized controlled trials on DanShen in the treatment of ischemic vascular disease. J Altern Complement Med 2009; 15: 557-565

49 He Y, Lu A, Lu C, Zha Y, Yan X, Song Y, Zeng S, Liu W, Zhu W, Su L, Feng X, Qian X, Tsang I. Symptom combinations assessed in traditional Chinese medicine and its predictive role in ACR20 efficacy response in rheumatoid arthritis. Am J Chin Med 2008; 36: 675-683

$50 \mathrm{He} \mathrm{Y,} \mathrm{Lu} \mathrm{A,} \mathrm{Zha} \mathrm{Y,} \mathrm{Tsang} \mathrm{I.} \mathrm{Differential} \mathrm{effect} \mathrm{on} \mathrm{symptoms} \mathrm{treated} \mathrm{with}$ traditional Chinese medicine and western combination therapy in RA patients. Complement Ther Med 2008; 16: 206-211

51 He Y, Lu A, Zha Y, Yan X, Song Y, Zeng S, Liu W, Zhu W, Su L, Feng X, Qian X, $\mathrm{Lu} C$. Correlations between symptoms as assessed in traditional Chinese medicine (TCM) and ACR20 efficacy response: a comparison study in 396 patients with rheumatoid arthritis treated with TCM or Western medicine. J Clin Rheumatol 2007; 13: 317-321

52 Shi N, Chen YJ, Wang J, Ni H. Clinical observation on the effect of Zengse Pill in treating patients with vitiligo of qi-stagnancy and blood-stasis syndrome type. Chin J Integr Med 2008; 14: 303-306

53 Wei Y, Hong YZ, Ye X. Effect of Tang No. 1 granule (1) in treating patients with impaired glucose tolerance. Chin J Integr Med 2008; 14: 298-302

54 Wang ZJ, Li HX, Wang JH, Zhang F. Effect of Shugan Jianpi Granule () on gut mucosal serotonin-positive cells in patients with irritable bowel syndrome of stagnated Gan-qi attacking Pi syndrome type. Chin J Integr Med 2008; 14: 185-189
55 Liu YF, Yu HM, Zhang C, Yang RX, Yan FF, Liu Y, Zhang Y, Zhao YX. Effects of Quyu Xiaoban capsules on clinical outcomes and platelet activation and aggregation in patients with unstable angina pectoris. J Altern Complement Med 2007; 13: 571-576

56 Sinclair-Lian N, Hollifield M, Menache M, Warner T, Viscaya J, Hammerschlag $R$. Developing a traditional Chinese medicine diagnostic structure for post-traumatic stress disorder. J Altern Complement Med 2006; 12: 45-57

57 Liu X, Du J, Cai J, Xu G, Lin A, Teng Q. Clinical systematic observation of Kangxin capsule curing vascular dementia of senile kidney deficiency and blood stagnation type. J Ethnopharmacol 2007; 112: 350-355

58 Zhou FS, Hu LJ, Wang RJ, Huang ZX, Luo Q. Study on clinical effect and mechanism of jianpi qingre huayu recipe. Chin J Integr Med 2007; 13: 22-26

59 Yang Y, Wang SC, Bai WJ, Li RL, Ai J. Evaluation by survival analysis on effect of traditional Chinese medicine in treating children with respiratory syncytial viral pneumonia of phlegm-heat blocking Fei syndrome. Chin J Integr Med 2009; 15: 95-100

60 Zhang Y, Chang J, Chi HH, Mao B, Tang WF, Wang L, Huang SZ, Li TQ Zhang RM. Randomized controlled trial on treatment of bronchial asthma of qi-deficiency cold syndrome type by pingchuan yiqi granule. Chin J Integr Med 2007; 13: 27-32

61 Teekachunhatean S, Kunanusorn P, Rojanasthien N, Sananpanich K, Pojchamarnwiputh S, Lhieochaiphunt S, Pruksakorn S. Chinese herbal recipe versus diclofenac in symptomatic treatment of osteoarthritis of the knee: a randomized controlled trial [ISRCTN70292892]. BMC Complement Altern Med 2004; 4: 19

62 Shi J, Xu GZ, Liu TT, Wang X, Shen LY, Li J, Hao W, Chen HX, Li SX, Lu L. A comparative clinical study of the effects of the traditional Chinese medicine Jinniu capsules and lofexidine on acute heroin withdrawal symptoms. Am J Drug Alcohol Abuse 2008; 34: 792-800

63 Kang L, Li B, Gao L, Li S, Wang D, Hu M, Li J. Tai-Kang-Ning, a Chinese herbal medicine formula, alleviates acute heroin withdrawal. Am J Drug Alcohol Abuse 2008; 34: 269-276

64 Chou PB, Morse CA, Xu H. A controlled trial of Chinese herbal medicine for premenstrual syndrome. J Psychosom Obstet Gynaecol 2008; 29: 185-192

65 Wong WC, Lee A, Lam AT, Li KT, Leung CY, Leung PC, Wong EL, Tang JL. Effectiveness of a Chinese herbal medicine preparation in the treatment of cough in uncomplicated upper respiratory tract infection: a randomised double-blinded placebo-control trial. Cough 2006; 2: 5

66 Li EK, Tam LS, Wong CK, Li WC, Lam CW, Wachtel-Galor S, Benzie IF, Bao YX, Leung PC, Tomlinson B. Safety and efficacy of Ganoderma lucidum (lingzhi) and San Miao San supplementation in patients with rheumatoid arthritis: a double-blind, randomized, placebo-controlled pilot trial. Arthritis Rheum 2007; 57: 1143-1150

67 Goldbach-Mansky $R$, Wilson M, Fleischmann $R$, Olsen $N$, Silverfield $J$, Kempf P, Kivitz A, Sherrer Y, Pucino F, Csako G, Costello R, Pham TH, Snyder C, van der Heijde D, Tao X, Wesley R, Lipsky PE. Comparison of Tripterygium wilfordii Hook F versus sulfasalazine in the treatment of rheumatoid arthritis: a randomized trial. Ann Intern Med 2009; 151: 229-240, W49-W51

68 Liu Y, Zhang L, Liu YF, Yan FF, Zhao YX. Effects of Bulbus allii macrostemi on clinical outcomes and oxidized low-density lipoprotein and plasminogen in unstable angina/non-ST-segment elevation myocardial infarction patients. Phytother Res 2008; 22: 1539-1543

$69 \mathrm{Gu}$ CL, Zhang YK, Fu YX, Yang SF, Li XQ. Effect of tiaozhi yanggan decoction in treating patients with non-alcoholic fatty liver. Chin J Integr Med 2007; 13: 275-279

70 Jiang $H$, Chen SH, Wen LZ. Effects of Jinye Baidu Granule on fetal growth and development with maternal active human cytomegalovirus infection. Chin J Integr Med 2006; 12: 250-254

71 Zhang MJ, Zhang GL, Yuan WB, Ni J, Huang LF. Treatment of abdominal compartment syndrome in severe acute pancreatitis patients with traditional Chinese medicine. World J Gastroenterol 2008; 14: 3574-3578

72 Chen ZX, Zhang SJ, Lao SX, Hu HT, Zhang CY, Guan SH, Gu YL. He Jie Tang in the treatment of chronic hepatitis B patients. World J Gastroenterol 2005; 11: 6638-6643

73 Li YM, Yang HZ, Guan WB, Ke QS, Dai M, Xie HP, Zhang SJ. Therapeutic effect of traditional Chinese medicine on coagulation disorder and accompanying intractable jaundice in hepatitis B virus-related liver cirrhosis patients. World J Gastroenterol 2008; 14: 6060-6064 
74 Tong GD, Zhou DQ He JS, Li SL, Peng LS. Effects of Shehuang Paste on hemodynamics, endotoxin, nitric oxide and endothelin-1 in patients with refractory cirrhotic ascites. Chin J Integr Med 2006; 12: 255-261

75 Zhao JX, Li XF, Wang XX. Effects of body-resistance strengthening and tumor-suppressing granules on immune adhesion function of red blood cells and expression of metastasis protein CD44 in tumor cells of patients with esophageal carcinoma. World J Gastroenterol 2007; 13: 4360-4364

76 Bao YX, Wong CK, Leung SF, Chan AT, Li PW, Wong EL, Leung PC, Fung KP, Yin YB, Lam CW. Clinical studies of immunomodulatory activities of Yunzhi-Danshen in patients with nasopharyngeal carcinoma. J Altern Complement Med 2006; 12: 771-776

77 Lu P, Liang QD, Li R, Niu HR, Kou XG, Xi HJ. Effect of traditional Chinese medicine on survival and quality of life in patients with esophageal carcinoma after esophagectomy. Chin J Integr Med 2006; 12: 175-179

78 Wu WY, Long SQ Zhang HB, Chai XS, Deng H, Xue XG, Wang B, Luo HY, Liu WS. Improvement of quality of life with Shenfu injection in non small cell lung cancer patients treated with gemcitabine plus cisplatin regimen. Chin J Integr Med 2006; 12: 50-54

79 Chan CK, Kuo ML, Shen JJ, See LC, Chang HH, Huang JL. Ding Chuan Tang, a Chinese herb decoction, could improve airway hyper-responsiveness in stabilized asthmatic children: a randomized, double-blind clinical trial. Pediatr Allergy Immunol 2006; 17: 316-322

80 Chang TT, Huang CC, Hsu CH. Clinical evaluation of the Chinese herbal medicine formula STA-1 in the treatment of allergic asthma. Phytother Res 2006; 20: 342-347

81 Hon KL, Leung TF, Ng PC, Lam MC, Kam WY, Wong KY, Lee KC, Sung YT, Cheng KF, Fok TF, Fung KP, Leung PC. Efficacy and tolerability of a Chinese herbal medicine concoction for treatment of atopic dermatitis: a randomized, double-blind, placebo-controlled study. Br J Dermatol 2007; 157: 357-363

82 Wen CP, Fan YS, Wang XC, Li XY, Lu KD. Effect of detoxification, removing stasis and nourishing yin method on corticosteroid-induced hyperlipidemia in patients with systemic lupus erythematosus. Chin J Integr Med 2007; 13: 180-184

83 Shao KD, Zhou YH, Shen YP, Ye BD, Gao RL, Zhang Y. Treatment of 37 patients with refractory idiopathic thrombocytopenic purpura by shengxueling. Chin J Integr Med 2007; 13: 33-36

84 Lin YK, Wong WR, Chang YC, Chang CJ, Tsay PK, Chang SC, Pang JH. The efficacy and safety of topically applied indigo naturalis ointment in patients with plaque-type psoriasis. Dermatology 2007; 214: 155-161

85 Kennedy S, Jin X, Yu H, Zhong S, Magill P, van Vliet T, Kistemaker C, Voors C, Pasman $W$. Randomized controlled trial assessing a traditional Chinese medicine remedy in the treatment of primary dysmenorrhea. Fertil Steril 2006; 86: 762-764

86 Yeh LL, Liu JY, Lin KS, Liu YS, Chiou JM, Liang KY, Tsai TF, Wang LH, Chen $C T$, Huang $C Y$. A randomised placebo-controlled trial of a traditional Chinese herbal formula in the treatment of primary dysmenorrhoea. PLoS One 2007; 2: e719

87 Hamazaki K, Sawazaki S, Itomura M, Huan M, Shibahara N, Kawakita T, Kobayashi S, Hamazaki T. No effect of a traditional Chinese medicine, Hochu-ekki-to, on antibody titer after influenza vaccination in man: a randomized, placebo-controlled, double-blind trial. Phytomedicine 2007: $14: 11-14$

88 Leung WK, Wu JC, Liang SM, Chan LS, Chan FK, Xie H, Fung SS, Hui AJ, Wong VW, Che CT, Sung JJ. Treatment of diarrhea-predominant irritable bowel syndrome with traditional Chinese herbal medicine: a randomized placebo-controlled trial. Am J Gastroenterol 2006; 101: 15741580

89 Mok TS, Yeo W, Johnson PJ, Hui P, Ho WM, Lam KC, Xu M, Chak K, Chan A Wong $H$, Mo F, Zee B. A double-blind placebo-controlled randomized study of Chinese herbal medicine as complementary therapy for reduction of chemotherapy-induced toxicity. Ann Oncol 2007; 18: 768-774

90 Wu XL, Sun WS, Zhang WG, Qiao CL, Ma QY, Zhang XQ. Study on effect of yishen capsule in preventing recurrence of chronic glomerulonephritis. Chin J Integr Med 2007; 13: 215-218

91 Wu XL, Sun WS, Zhang WG, Qiao CL, Liu RX. Clinical study of Trilogy Detoxicating Therapy combined with routine Western medicine on patients with chronic renal failure. Chin J Integr Med 2008; 14: 98-102

92 Zhou LY, Shan ZZ, You JL. Clinical observation on treatment of colonic cancer with combined treatment of chemotherapy and Chinese herbal medicine. Chin J Integr Med 2009; 15: 107-111
93 Fukunaga K, Hida N, Ohnishi K, Ohda Y, Yoshida K, Kusaka T, Jinno Y, Nagase K, Nakamura S, Kadobayashi M, Miwa H, Matsumoto T. A suppository Chinese medicine (xilei-san) for refractory ulcerative proctitis: a pilot clinical trial. Digestion 2007; 75: 146-147

94 Miyaoka T, Furuya M, Yasuda H, Hayashia M, Inagaki T, Horiguchi J. Yigan san for the treatment of borderline personality disorder: an openlabel study. Prog Neuropsychopharmacol Biol Psychiatry 2008; 32 : 150-154

95 Baurle P, Suter A, Wormstall $H$. Safety and effectiveness of a traditional ginkgo fresh plant extract - results from a clinical trial. Forsch Komplementmed 2009; 16: 156-161

96 Cheng JF, Lu ZY, Su YC, Chiang LC, Wang RY. A traditional Chinese herbal medicine used to treat dysmenorrhoea among Taiwanese women. J Clin Nurs 2008; 17: 2588-2595

97 Song EF, Xiang $Q$ Ren KM, Hu JC, Wu F, Gong MF, Zhang H, Bi HM. Clinical effect and action mechanism of Weicao Capsule in treating gout. Chin J Integr Med 2008; 14: 103-106

98 Fang S, Wu Z, Zhang X, Liu Y, Wang W, Chai L, Cai H, Yi J, Wang L, Chen Y, Lv X, Huang $Y$, Wang $R$, Chen P. Clinical observation on Yi Sui Sheng Xue Granule on treating 156 patients with beta-thalassemia major and the molecular mechanism study. Biol Pharm Bull 2007; 30: 2084-2087

99 Liu SX, Jiang L, Liu YG, He YQ Liang X, Kong WW, Chen J. Study on the efficacy and safety of Xueyou Mixture in treating hemophilia. Chin J Integr Med 2007; 13: 141-144

100 Doctorow EL. The book of Daniel. New York: Random House; 1971

101 Lachin JM, Matts JP, Wei LJ. Randomization in clinical trials: conclusions and recommendations. Control Clin Trials 1988; 9: 365-374

102 Stolberg HO, Norman G, Trop I. Randomized controlled trials. AJR Am J Roentgenol 2004; 183: 1539-1544

103 Vader JP. Randomised controlled trials: A User's guide. BMJ 1998; 317: 1258

104 Jadad AR, Rennie $D$. The randomized controlled trial gets a middleaged checkup. JAMA 1998; 279: 319-320

105 Schulz KF, Chalmers I, Hayes RJ, Altman DG. Empirical evidence of bias. Dimensions of methodological quality associated with estimates of treatment effects in controlled trials. JAMA 1995; 273: 408-412

106 Wu T, Li Y, Bian Z, Liu G, Moher D. Randomized trials published in some Chinese journals: how many are randomized? Trials 2009; 10: 46

107 Bian ZX, Moher D, Dagenais S, Li YP, Liu L, Wu TX, Miao JX. Improving the quality of randomized controlled trials in Chinese herbal medicine, part II: control group design. Zhong Xi Yi Jie He Xue Bao 2006; 4: $130-136$

$108 \mathrm{Lu} A$ P, Ding XR, Chen KJ. Current situation and progress in integrative medicine in China. Chin J Integr Med 2008; 14: 234-240

109 Lu AP, Jia HW, Xiao C, Lu QP. Theory of traditional Chinese medicine and therapeutic method of diseases. World J Gastroenterol 2004; 10 : $1854-1856$

110 van Wietmarschen H, Yuan K, Lu C, Gao P, Wang J, Xiao C, Yan X, Wang $M$, Schroen J, Lu A, Xu G, van der GreefJ. Systems biology guided by Chinese medicine reveals new markers for sub-typing rheumatoid arthritis patients. J Clin Rheumatol 2009; 15: 330-337

111 Lu AP, Zhang SS, Zha QL, Ju DH, Wu H, Jia HW, Xiao C, Li S, Jian H. Correlation between CD4, CD8 cell infiltration in gastric mucosa, Helicobacter pylori infection and symptoms in patients with chronic gastritis. World J Gastroenterol 2005; 11: 2486-2490

$112 W u$ J, Chen KJ, Wu YJ. Phagocytosis of platelet in coronary heart disease patients with blood-stasis syndrome. Chin Med J (Engl) 1993; 106: 546-549

113 He Y, Zha Q Liu D, Lu A. Relations between serum IgA level and cartilage erosion in 436 cases of rheumatoid arthritis. Immunol Invest 2007: 36: 285-291

114 Zha Q He Y, Lu Y, Lu A. Relationship between platelet counts and cartilage erosion in 436 cases of rheumatoid arthritis. Clin Chim Acta 2006; 371: 194-195

115 Leung KF, Liu FB, Zhao L, Fang JQ Chan K, Lin LZ. Development and validation of the Chinese Quality of Life Instrument. Health Qual Life Outcomes 2005; 3: 26

116 Zhao L, Chan K. Building a bridge for integrating Chinese medicine into conventional healthcare: observations drawn from the development of the Chinese quality of life instrument. Am J Chin Med 2005; 33 : 897-902 
117 Donald LP. Patient-reported outcomes (PROs): an organizing tool for concepts, measures, and applications. Qual Life Newslett 2003; 31: $1-5$

118 Acquadro C, Berzon R, Dubois D, Leidy NK, Marquis P, Revicki D, Rothman $M$. Incorporating the patient's perspective into drug development and communication: an ad hoc task force report of the PatientReported Outcomes (PRO) Harmonization Group meeting at the Food and Drug Administration, February 16, 2001. Value Health 2003; 6: 522-531

119 Burke L. Acceptable evidence for pharmaceutical advertising and labeling. DIA Workshop on Pharmacoeconomics and Quality of Life Labeling and Marketing Claims. New Orleans: Drug Information Association; 2000

120 Chan K. Chinese medicinal materials and their interface with Western medical concepts. J Ethnopharmacol 2005; 96: 1-18

121 Trushelm MR, Berndt ER, Douglas FL. Stratified medicine: strategic and economic implications of combing drugs and clinical biomarkers. Nat Rev Drug Discov 2007; 6: 287-293

122 Chui SH, Shek SL, Fong MY, Szeto YT, Chan K. A panel study to evaluate quality of life assessments in patients suffering from allergic rhinitis after treatment with a Chinese herbal nasal drop. Phytother Res 2010; 24: 609-613

123 Chui SH, Chow FC, Chan K, Fu S, Seto YT. Slimpid may boost plasma IGF-1 level and improve the quality of life in patients with risk of developing metabolic syndrome. J Complement Integr Med 2008; 5: 1-13

124 Chui SH, Chan K, Chui AK, Shek LS, Wong RN. The effects of a Chinese medicinal suppository (Vitalliver) on insulin-like growth factor 1 and homocysteine in patients with hepatitis B infection. Phytother Res 2005; 19: 674-678
125 Chui SH, Chan K, Wong RN, Chen KJ. A panel study on the effects of a Chinese medicinal suppository, Vigconic VI-28, on insulin-like growth factor 1 and homocysteine in healthy men. Methods Find Exp Clin Pharmacol 2004; 26: 349-355

126 Shen $Y H$, Nahas $R$. Complementary and alternative medicine for treatment of irritable bowel syndrome. Can Fam Physician 2009; 55: $143-$ 148

127 Ernst E. Methodological aspects of Traditional Chinese Medicine (TCM). Ann Acad Med Singapore 2006; 35: 773-774

128 Ernst E, Pittler MH. Alternative therapy bias. Nature 1997; 385: 480

129 Stevinson C, Pittler MH, Ernst E. Garlic for treating hypercholesterolemia. A meta-analysis of randomized clinical trials. Ann Intern Med 2000; 133: 420-429

$130 \mathrm{Ko}$ R. Adverse reactions to watch for in patients using herbal remedies. West J Med 1999; 171: 181-186

131 Jiang M, Zhao J, Lu A, Zha Q He Y. Does gastrointestinal adverse drug reaction influence therapeutic effect in the treatment of rheumatoid arthritis? J Altern Complement Med 2010; 16: 143-144

132 Phillips KA, Veenstra DL, Oren E, Lee JK, Sadee W. Potential role of pharmacogenomics in reducing adverse drug reactions: a systematic review. JAMA 2001; 286: 2270-2279

133 Meyer UA. Pharmacogenetics and adverse drug reactions. Lancet 2000; 356: 1667-1671

134 Wessels JA, van der Kooij SM, le Cessie S, Kievit W, Barerra P, Allaart CF, Huizinga TW, Guchelaar HJ. A clinical pharmacogenetic model to predict the efficacy of methotrexate monotherapy in recent-onset rheumatoid arthritis. Arthritis Rheum 2007; 56: 1765-1775 